\title{
Filosofía ambiental de campo y conservación biocultural en el Parque Etnobotánico Omora: Aproximaciones metodológicas para ampliar los modos de integrar el componente social ("S") en Sitios de Estudios Socio-Ecológicos a Largo Plazo (SESELP)
}

Field environmental philosophy and biocultural conservation at the Omora Ethnobotanical Park: Methodological approaches to broaden the ways of integrating the social component (“S”) in Long-Term Socio-Ecological Research (LTSER) Sites

RICARDO ROZZI 1 , 2, 3, *, CHRISTOPHER B. ANDERSON ${ }^{1,2,3}$, J. CRISTÓBAL PIZARRO ${ }^{1,2}$, FRANCISCA MASSARDO $^{1,2}$, YANET MEDINA ${ }^{1,2}$, ANDRÉS O. MANSILLA ${ }^{1,2}$, JAMES H. KENNEDY ${ }^{1,3}$, JAIME OJEDA ${ }^{1,2}$, TAMARA CONTADOR ${ }^{1,3}$, VERÓNICA MORALES ${ }^{2}$, KELLI MOSES $^{3}$, ALEXANDRIA POOLE ${ }^{3}$, JUAN J. ARMESTO ${ }^{2}$ \& MARY T. KALIN ${ }^{2}$

\footnotetext{
${ }^{1}$ Omora Ethnobotanical Park and Department of Natural Sciences and Resources, Science Faculty, Universidad de Magallanes, Puerto Williams and Punta Arenas, Chile

${ }^{2}$ Institute of Ecology \& Biodiversity, Casilla 653, Santiago, Chile

${ }^{3}$ Sub-Antarctic Biocultural Conservation Program, Department of Philosophy and Religion Studies and Department of Biological Sciences, University of North Texas, Denton TX, USA

*Autor correspondiente: rozzi@unt.edu
}

\begin{abstract}
RESUMEN
Para resolver los problemas derivados del cambio medioambiental global, los científicos y tomadores de decisiones reconocen que es necesario integrar más ampliamente el componente social o factor humano en la investigación ecológica. Proponemos que para lograr esta integración las redes de Sitios de Estudios Socio-Ecológicos a Largo Plazo (SESELP) ofrecen una plataforma ideal, porque los sitios permiten abordar singularidades ecológicas, culturales y políticas a escala local, a la vez que integrar escalas globales a través del trabajo colaborativo en redes de sitios. Sin embargo, este trabajo socioecológico todavía requiere articular de mejor manera los programas desarrollados a múltiples escalas geográficas, ecológicas y políticas. Además, hasta el momento el componente social considerado en los programas SESELP ha sido fundamentalmente económico, dejando fuera la dimensión ética. La integración de la ética de manera sistemática en los programas SESELP está severamente limitada por la carencia de metodologías. Para contribuir a resolver esta limitación, hemos desarrollado una aproximación metodológica que denominamos “filosofía ambiental de campo". Esta aproximación integra las ciencias ecológicas y la ética ambiental en educación y conservación biocultural a largo-plazo a través de un ciclo de cuatro pasos interrelacionados: i) investigación interdisciplinaria ecológica y filosófica, ii) composición de metáforas y comunicación a través de relatos simples, iii) diseño de experiencias de campo guiadas con un sentido ecológico y ético, y iv) habilitación de áreas de conservación in situ. Este ciclo se ha definido a posteriori analizando las experiencias efectivas del programa de investigación, educación y conservación biocultural del Parque Etnobotánico Omora, en la Reserva de Biosfera Cabo de Hornos (RBCH). El programa de Magíster en Ciencias con mención en Conservación Subantártica de la Universidad de Magallanes (UMAG) está adoptando este ciclo como una metodología estructurada para el diseño de tesis y mallas curriculares de estudiantes que están generando innovadoras actividades educativas y de ecoturismo, como el "Ecoturismo con Lupa” y el "Birding Ético”. Para articular programas de trabajo múltiples escalas, el Parque Omora funciona a escala local como un centro de investigación en la $\mathrm{RBCH}$, a nivel nacional como cofundador y sitio más austral de la red chilena SESELP coordinada por el Instituto de Ecología y Biodiversidad (IEB), y a nivel internacional como una reserva y estación de campo del Programa de Conservación Biocultural Subantártica, coordinado por la UMAG, IEB y la Universidad de North Texas (UNT). Esta organización en unidades anidadas ha permitido articular de manera sinérgica el trabajo a escalas locales, nacionales e internacionales. La investigación colaborativa ha: 1) conducido al descubrimiento de singularidades de la diversidad biológica y cultural en la remota ecorregión subantártica de Magallanes, 2) ha posibilitado programas de educación y conservación trabajando con múltiples actores sociales e instituciones, y 3) incorporado la filosofía ambiental en la investigación socioecológica. De esta manera, el programa del Parque Omora contribuye a ampliar la definición del componente social ("S") en las redes SESELP, y a generar metodologías para integrar, a múltiples escalas, dimensiones ecológicas y éticas en programas de investigación socioecológica, como
\end{abstract}


también de educación y conservación biocultural, que podrían ser implementadas y evaluadas en otros sitios o redes SESELP.

Palabras clave: ética ambiental, Iniciativa para una Biosfera Sustentable, metáfora, Reserva de Biosfera Cabo de Hornos, subantártico.

\begin{abstract}
In order to effectively address the problems derived from global environmental change, environmental scientists, citizens and decision-makers now recognize the need to integrate more fully the human or social component into ecological research. We propose that to achieve this integration, Long-Term Socio-Ecological Research (LTSER) networks offer an ideal platform, because such sites enable research at ecological, cultural, and political local scales, and at the same time allow addressing these issues at a global scale. However, this socio-ecological work still requires better articulation of programs developed at multiple geographic, ecological and political scales. In addition, until now the social component considered in LTSER programs has focused on economic factors, omitting ethical dimensions. A central reason for this omission is the lack of methodologies to systematically integrate ethics into LTSER programs. As a contribution to resolve this limitation, here we develop a methodological approach that we call "field environmental philosophy.” It integrates ecological research and environmental ethics into biocultural education and conservation through an interrelated four-step cycle: i) interdisciplinary ecological and philosophical research, ii) composition of metaphors, and communication through simple narratives, iii) design of guided field experiences with an ecological and ethical orientation, and iv) implementation of in situ conservation areas. This cycle has been defined a posteriori, by analyzing successful experiences of biocultural research, education and conservation program at the Omora Ethnobotanical Park (OEP) in the Cape Horn Biosphere Reserve (CHBR). The Masters of Science in Subantarctic Conservation at the University of Magallanes (UMAG) adopted this cycle as a structured methodology to design theses and academic curricula for students who are creating innovative educational and ecotourism activities, such as "Ecotourism with a Hand Lens" and "Ethical Birding." To articulate the programs at multiples scales, the OEP functions at the local scale as a research center in the CHBR, at the national level as a cofounder and southernmost site of the Chilean LTSER network coordinated by the Institute of Ecology and Biodiversity (IEB), Chile, and at the international level as a reserve and field station of the Subantarctic Biocultural Conservation Program that is coordinated by UMAG, IEB and the University of North Texas (UNT). This organization of nested units has permitted to synergistically articulate the work at local, national and international scales. Collaborative research has led to the discovery of biological and cultural diversity singularities in the remote Magellanic subantarctic ecoregion, enabled education and conservation work with multiple social actors and institutions, and has strengthened the incorporation of environmental philosophy into socio-ecological research. In this way, OEP's program is contributing to broaden the definition of the social ("S") component in LTSER, and to generate methodologies to integrate, at multiple scales, ecological and ethical dimensions into socioecological research, as well as biocultural education and conservation programs, which could be implemented and assessed at other LTER sites.
\end{abstract}

Key words: Cape Horn Biosphere Reserve, environmental ethics, metaphor, subantarctic, Sustainable Biosphere Initiative.

\section{INTRODUCCIÓN}

El cambio medioambiental global tiene una dimensión ética esencial por al menos dos razones. Primero, las causas últimas de la crisis ambiental actual radican en el modo de relación establecido por la sociedad industrial con el mundo natural (White 1967, Bormann \& Kellert 1991, Rozzi 2001). En consecuencia, para confrontar esta crisis se requieren cambios éticos en la valoración de los ecosistemas, la vida humana y no humana, y en las prácticas productivas y políticas de mercado que afectan a ambas. La ética ambiental concierne tanto a las sociedades humanas como a la naturaleza y procura el bienestar de ambas. Segundo, las perspectivas éticas prevalecientes proponen que la pregunta acerca de qué debemos hacer frente al cambio medioambiental global involucra decisiones éticas. Bajo esta perspectiva, las ciencias contribuyen a identificar y caracterizar las causas próximas de la crisis ambiental global, y ayudan a definir qué podemos hacer. Pero definir qué debemos hacer involucra esencialmente una respuesta ética, sujeta a procesos de conflicto y deliberación entre diversos actores sociales con intereses y valores contrastantes (Broome 2008). Aquí proponemos una aproximación ética alternativa que supera esta dicotomía disciplinaria entre el qué debemos hacer (derivado de la ética) y el qué podemos hacer 
(derivado de la ciencia). Esta aproximación es central en la interrelaciones entre los modos de investigar la naturaleza y los modos de habitar en ella (Rozzi 1999). En esta dinámica interdisciplinaria, las ciencias ecológicas asumen un papel crucial en motivar cambios éticos en los modos de relación entre la sociedad contemporánea y la biosfera fundados en cambios en los modos en que los seres humanos perciben, conocen y comprenden ecológicamente la naturaleza (Rozzi 1999).

Bajo esta perspectiva en que las ciencias ecológicas y la ética ambiental se informan recíprocamente, las redes de Sitios de Estudios Socio-Ecológicos a Largo Plazo (SESELP) podrían jugar un papel científico y ético crítico. Metafóricamente ellas al representar "ojos" con que la sociedad contemporánea explora los ecosistemas, la biodiversidad y las relaciones de los seres humanos con ellos. Tanto para los científicos como para los tomadores de decisiones, educadores y la sociedad en general, momento a momento, en diversas regiones, las redes SESELP generan una imagen ecológica del mundo (Franklin et al. 1990). Para cumplir con esta misión, las redes SESELP deben forjar los mejores "lentes conceptuales" al mismo tiempo que los mejores "sensores tecnológicos" para investigar y monitorear los sistemas socio- ecológicos. En esta tarea, la filosofía y la ética ambiental asumen una tarea tan relevante como la ingeniería y las ciencias ambientales.

La incorporación de métodos filosóficoscientíficos-tecnológicos amplía el espectro de variables socioecológicas investigadas y promueve la consideración de cosmovisiones ecológicas albergadas por distintas expresiones culturales (arte, religión, ética) y por diversos grupos étnicos, con sus lenguajes y prácticas ecológicas (Callicott 1996, Hargrove 1997, Rozzi 1997). A través de la integración de métodos filosóficos-científicostecnológicos, las redes SESELP pueden contribuir significativamente a captar de mejor manera, al mismo tiempo que favorecer, la expresión de la vasta diversidad de conocimientos ecológicos tradicionales y valores ético-ambientales exhibidos por diversos grupos socioculturales que habitan en las heterogéneas ecorregiones del planeta. En consecuencia, la escala internacional de las redes SESELP amplía tanto la escala geográfica como los espectros de diversidad ecológica y cultural.

Con esta visión en su participación en la Red Chilena SESELP, el Programa de Investigación, Educación y Conservación Biocultural Subantártica del Parque Etnobotánico Omora quiere contribuir a: (i) la incorporación de la filosofía y la ética ambiental en los estudios socioecológicos a largo plazo, y (ii) a consolidar una mayor cobertura internacional de las redes SESELP.

Para ser efectivos en el contexto global de la economía y cambio medioambiental actual, los programas de conservación biológica y cultural deben abordar múltiples escalas geográficas y políticas, y considerar los contextos socioculturales y ecológicos de cada ecorregión. Con el fin de prevenir la imposición ciega de modelos de desarrollo globales sobre realidades singulares, y promover en cambio la expresión de diversas formas de vida y de conocimiento ecológico tradicional de comunidades regionales, exponemos aquí una aproximación metodológica que denominamos "filosofía ambiental de campo". Bajo este método, ecólogos, filósofos y otros profesionales participan en proyectos de conservación biocultural a largo plazo, teniendo encuentros directos "cara a cara" con la diversidad biocultural, que a través de esta experiencia in situ deja de ser meramente un concepto y comienza a ser una experiencia de cohabitación con diversos seres vivientes, historias de vidas e instituciones que regularmente permanecen fuera de los ámbitos considerados en la educación formal y la toma de decisiones (Rozzi et al. 2005, 2008a). La práctica de la filosofía ambiental de campo combina métodos y conceptos de la ética "universal" enseñada en las universidades con aquellos de la investigación socioecológica. Esta metodología híbrida contribuye a: (i) contextualizar ecológica, cultural y políticamente las propuestas éticas y científicas, y (ii) establecer nuevos tipos de colaboraciones entre la ecología y las humanidades, (Rozzi et al. 2003, Callicott et al. 2007, Berghoefer et al. 2008).

Para implementar estas integraciones interdisciplinarias y para articular escalas locales y globales, las redes SESELP pueden jugar un papel central más allá de una mera plataforma de investigación. Para ello ampliamos la aproximación prevaleciente de 
"caso de estudio" hacia una metodología colaborativa que vincula la escala local del sitio con escalas nacionales e internacionales, que son esenciales para integrar de manera efectiva la investigación con procesos sociales, en general, y con la educación y la conservación biocultural, en particular (Rozzi et al. 2008a).

Desde la década de los 1980, un número creciente de científicos y humanistas ha hecho reiterados llamados a integrar la ecología, la economía y la ética, para abordar problemas asociados al cambio climático global, las aceleradas pérdidas de biodiversidad, la lluvia ácida, la degradación de hábitats y otras dimensiones del cambio medioambiental global (Bormann \& Kellert 1991). Hoy, los científicos, tomadores de decisiones y la ciudadanía, están conscientes que los problemas medioambientales globales requieren integrar dimensiones ecológicas y sociales (Holling 2004, Jax \& Rozzi 2004, Rozzi et al. 2006a, Anderson et al. 2008). Más aún, el vínculo entre el bienestar humano y de los demás seres vivos ha llegado a ser más evidente (e.g., Rozzi \& Feinsinger 2001, Millennium Ecosystem Assessment 2005). Como respuesta, se han desarrollado programas académicos interdisciplinarios en torno a conceptos socioecológicos, tales como la restauración ecológica (Jordan et al. 1987, Elliot 1994, Palmer \& Filoso 2007) y la economía ecológica (Daly \& Townsend 1993, Daily 1997, Farber et al. 2006). Estos nuevos programas han generado nuevos conceptos como bienes y servicios ecosistémicos, y salud y restauración ecosistémica, estimulando la investigación científica, el desarrollo de políticas y estrategias de conservación. En este escenario, los programas SESELP han llegado a incluir de manera cada vez más efectiva estudios "socioeconómicos" (Haber et al. 2006). Sin embargo, la integración de la ética ambiental y de aproximaciones culturales y filosóficas en los programas SESELP todavía representa fundamentalmente una tarea por hacer.

Con el fin de contribuir a resolver los desafíos anteriores, en este artículo proponemos aproximaciones metodológicas que han sido efectivas para: i) articular las escalas locales, nacionales e internacionales en programas transdisciplinarios de investigación socioecológica a largo plazo, y ii) para integrar la investigación ecológica y la ética ambiental en programas de educación y conservación biocultural desarrollados en un sitio de estudios socioecológicos a largo plazo.

Elaboramos estas aproximaciones metodológicas basados en la experiencia ganada durante los primeros diez años del programa de investigación, educación y conservación biocultural del Parque Etnobotánico Omora en la región del archipiélago del Cabo de Hornos (Fig. 1). El Parque Omora es cofundador de la Red Chilena SESELP coordinada por el Instituto de Ecología y Biodiversidad (IEB), representando su sitio más austral y menos antropogénicamente perturbado. La remota región de Cabo de Hornos alberga todavía una pequeña población humana $(2,500) \mathrm{y}$ vastas áreas marinas y terrestres con bajo impacto humano (Mittermeier et al. 2003). Sin embargo, durante las dos últimas décadas estas áreas prístinas han enfrentado rápidamente presiones de crecimiento y desarrollo, turismo masivo, acuicultura y otras formas de explotación de recursos naturales. En este contexto, el equipo de investigación del Parque Omora ha asumido acciones proactivas de conservación y desarrollado metodologías que podrían ser útiles para ampliar la integración de dimensiones sociales y ecológicas a múltiples escalas geográficas, político-organizacionales y culturales en otros sitios de las redes SESELP chilena e internacional.

I. ARTICULACIÓN DE ESCALAS LOCALES, NACIONALES E INTERNACIONALES EN LA ECORREGIÓN SUBANTÁRTICA DE MAGALLANES

El escenario de cambio ambiental global, como también de libre mercado y políticas globales actuales, demandan que los programas de investigación, educación y conservación a escala local-regional se articulen con iniciativas a escala nacional e internacional. Es importante que los actores locales aprendan sobre políticas globales, y a la vez que eduquen a los actores globales acerca de las peculiaridades de la diversidad biocultural regional. Esta dinámica dialógica local-global favorece la incorporación de formas de 
conocimiento y criterios locales y globales en procesos de construcción colaborativa de alternativas de desarrollo sustentable y conservación biocultural. De no ser así, se corre el riesgo que se omitan las singularidades de la diversidad biológica y cultural regional debido a políticas y procesos de toma de decisiones orientados por criterios puramente globales, que conducen a una homogeneización biológica y cultural no deseable. Por lo tanto, para prevenir procesos de homogeneización biocultural (i.e. imposición, intencionada o accidental, de biotas, lenguajes, patrones culturales, estructuras administrativas, educativas y económicas globales, incluso en lugares remotos como Cabo de Hornos), es crítico que los participantes en iniciativas locales establezcan diálogos y trabajos de colaboración con investigadores, políticos y tomadores de decisiones que se desenvuelven en escalas más amplias. Por esta razón, el programa de investigación socioecológica a largo plazo del Parque Omora ha definido una estructura que organiza sus actividades de investigación, educación y conservación con diversas instituciones en tres escalas interdependientes y sinérgicas: (I.1) localregional, (I.2) nacional, e (I.3) internacional.

\section{I.1. Escala local-regional: el Parque Etnobotáni- co Omora}

El Parque Omora tiene una extensión de aproximadamente 1,000 ha, que corresponden a una concesión gratuita por 25 años del Ministerio de Bienes Nacionales a la Universidad de Magallanes y a la Fundación Omora. Estas instituciones coejecutan sus programas en colaboración con el Instituto de Ecología y Biodiversidad (IEB). Para su trabajo a escala local-regional, el Parque Omora ha cumplido un papel como centro científico para la Reserva de Biosfera Cabo de Hornos (RBCH). Para esta función, ha tomado a la Estación Charles Darwin en la Reserva de Biosfera Galápagos, Ecuador, como un modelo para desarrollar programas de investigación que también proporcionen contenidos y criterios para el turismo sustentable y la conservación. Para llevar a cabo esta misión a escala local-regional, el Parque Omora ha asumido tres funciones eco- sociales principales: i) conservación de la cuenca hidrográfica del río Róbalo, ii) identificación y protección de un Sitio Prioritario para la Conservación de la Biodiversidad Subantártica, y iii) establecimiento de un sitio para la conducción de programas de investigación en filosofía ambiental y ecología.

I.1.1. Conservación de la cuenca hidrográfica más austral del mundo

El Parque Omora protege la cuenca hidrográfica del río Róbalo, que abastece de agua bebestible a la ciudad de Puerto Williams, capital de la Provincia Antártica Chilena y el poblado más austral del mundo (Fig. 1). Al proporcionar un sólido conocimiento acerca de las comunidades biológicas, junto con proponer e implementar medidas para conservar la integridad ecosistémica de esta cuenca, el Parque Omora contribuye a la regulación natural en el largo plazo tanto del flujo como de la calidad del agua. Un descubrimiento de especial relevancia ha sido la singularidad de la vegetación de la cuenca del río Róbalo en cuanto a su alta diversidad de flora no vascular, característica de bosques y tundras subantárticas (Rozzi et al. 2006a, 2008).

Las plantas no vasculares juegan un papel ecológico crítico en la regulación del flujo hídrico; contribuyen a evitar inundaciones cuando ocurren eventos de alta precipitación, e impiden la disminución drástica de los caudales durante períodos de sequía. Las briofitas, líquenes y otros tipos de vegetación también contribuyen a mantener la calidad del agua. Por un lado, previenen la erosión del suelo y, por otro, actúan como un filtro que retiene los sedimentos suspendidos en el agua, especialmente en los hábitats de turberas. La calidad del agua es crítica para el buen funcionamiento de las empresas pesqueras de enlatados establecidas en Cabo de Hornos. Para esta industria el uso de aguas con alto grado de pureza es crucial para evitar procesos químicos, como la oxidación de los tarros de conserva de centolla (Lithodes santolla Jacquinot, 1853) y centollón (Paralomis granulosa Jacquinot, 1874), especies que constituyen casi la totalidad de su producción. 

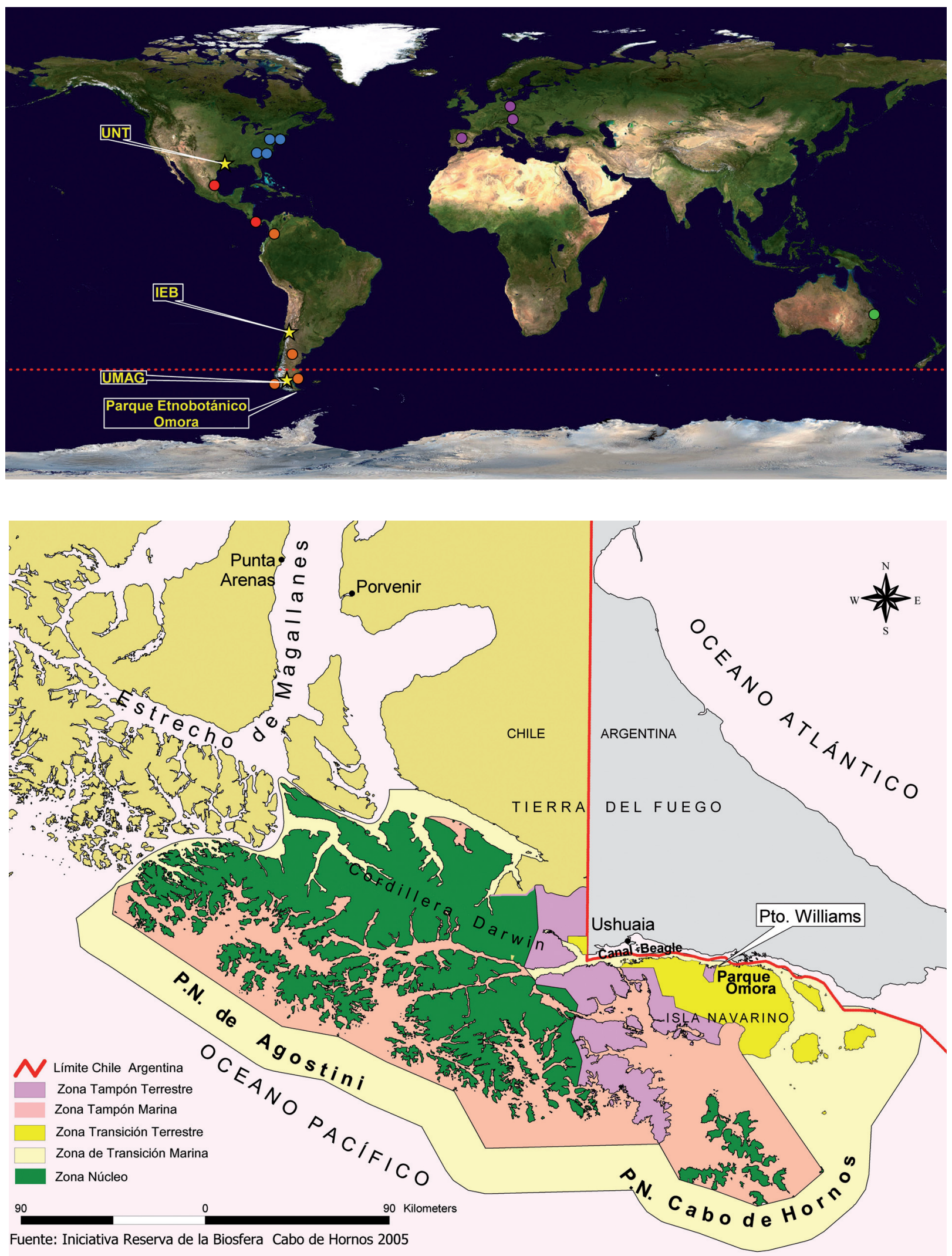

Figura. 1: 

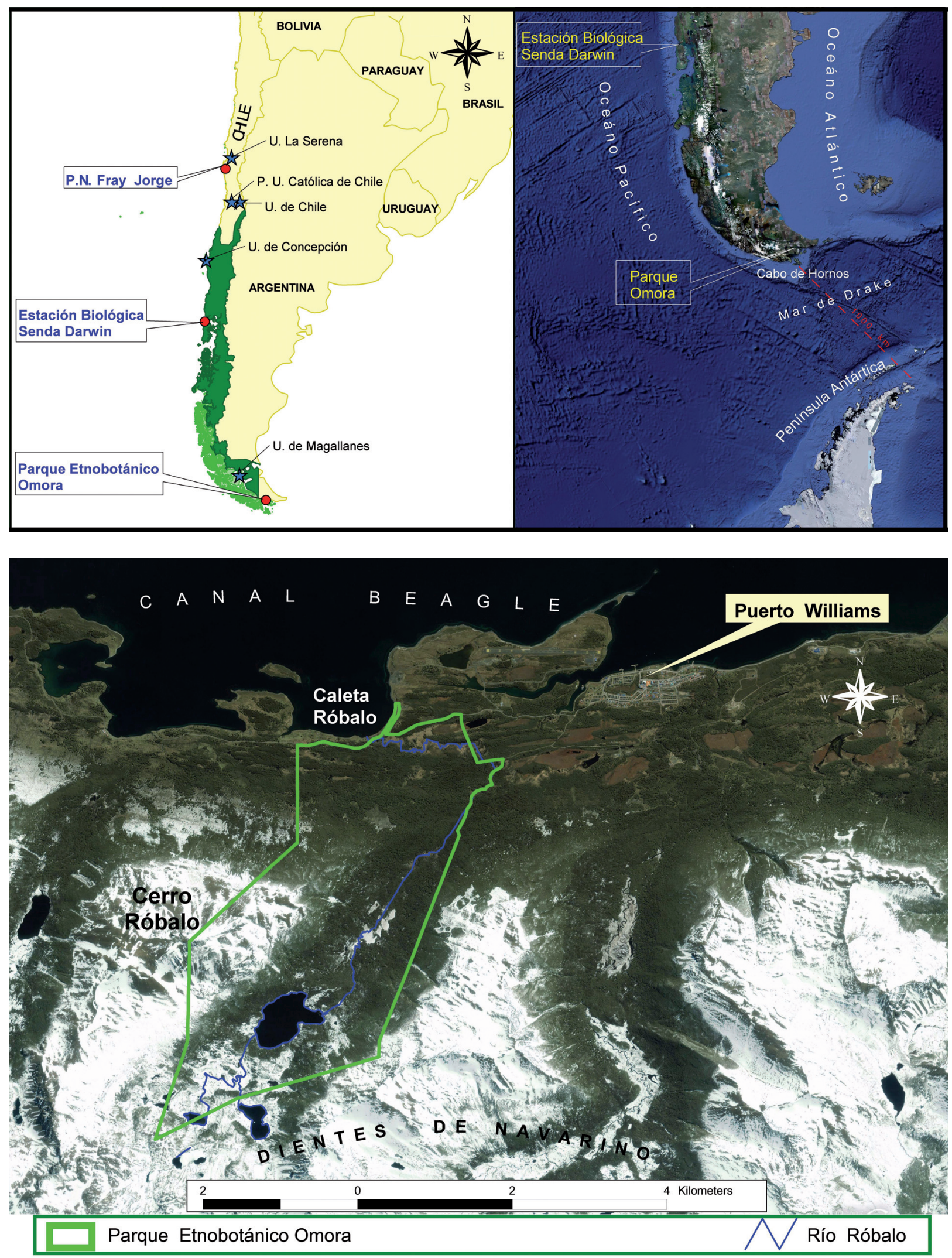
Fig. 1: Múltiples escalas de trabajo de los programas de investigación, educación y conservación biocultural asociados al Parque Etnobotánico Omora.

A. Escala internacional = Programa de Conservación Biocultural Subantártica coordinado por la University of North Texas (UNT), Instituto de Ecología y Biodiversidad (IEB) y Universidad de Magallanes (UMAG) (estrellas amarillas). Sobre la imagen satelital del mundo, los círculos señalan los colaboradores centrales en los Estados Unidos de Norteamérica (celeste = Institute of Ecosystem Studies, University of Coneccticut, University of Georgia y The Ecological Society of America), en México y Costa Rica (rojo = Red IberoMaB en el Instituto de Ecología de Xalapa y la Universidad de Cooperación Internacional de Costa Rica), en Sudamérica (naranja = la Universidad Nacional de Colombia, el Instituto Antártico Chileno, el Centro Austral de Investigaciones Cientificas Ushuaia - Argentina, y la Red AVINA Patagonia), en Europa (lila = el Centro de Investigaciones Ambientales UFZ-Leipzig, Alemania, la Universidad Complutense de Madrid, España, y el Parco Dolomiti Bellunesi, Italia), y en Australia (verde = University of Sunshine Coast). Por debajo de la línea roja horizontal en el extremo suroeste de Sudamérica se extiende la ecorregión subantártica de Magallanes. La flecha indica la ubicación del Parque Etnobotánico Omora en la Reserva de Biosfera Cabo de Hornos, que alberga los ecosistemas forestales más australes del mundo y constituye el punto continental más cercano a la Antártica $(1,000 \mathrm{~km})$.

B. Escala nacional = Red Chilena de Sitios de Estudios Socio-Ecológicos a Largo Plazo (SESELP) coordinada por el IEB. En el mapa se indica la ubicación de las cinco universidades involucradas (estrellas azules) y los tres sitios SESELP (círculos rojos) distribuidos a lo largo de un amplio gradiente latitudinal en la costa chilena del Océano Pacífico. Estos sitios abarcan todo el ámbito de distribución latitudinal de los bosques templados de Sudamérica, desde los ecosistemas semiárido en Fray Jorge, hasta los bosques templados siempreverdes lluviosos en Chiloé, y subantárticos en Cabo de Hornos. Junto a gradientes de precipitaciones, temperatura y fotoperíodos, estos sitios cubren un gradiente de perturbación antrópica, desde urbano-rural en el norte hasta prístino en el extremo sur. El sitio del Parque Nacional Fray Jorge y el Parque Omora están localizados en reservas de biosfera de la UNESCO, mientras que la Senda Darwin en Chiloé es una reserva privada asociadas al PN Chiloé.

C. Escala local-regional = Reserva de Biosfera Cabo de Hornos $(\mathrm{RBCH})$. Mapa del extremo sur de Sudamérica señalando la zonificación de la $\mathrm{RBCH}$. En verde: zonas núcleo que corresponden en su totalidad a áreas incluidas dentro de los parques nacionales Alberto de Agostini y Cabo de Hornos, administrados por la Corporación Nacional Forestal (CONAF). En rosado oscuro: zonas tampón terrestres que corresponden casi totalmente a tierras fiscales administradas por el Ministerio de Bienes Nacionales y la franja costera bajo la tuición del Ministerio de Defensa de Chile. En rosado claro: zonas tampón marinas ubicadas en aguas interiores administradas por el Ministerio de Defensa de Chile y la Subsecretaría de Pesca. En amarillo oscuro: zonas de transición terrestres donde se encuentra la ciudad de Puerto Williams y otros pequeños asentamientos humanos. En amarillo claro: zonas de transición marinas que abarcan el área que rodea a las zonas tampón marinas. Nótese que el Parque Omora, en la costa norte de la isla Navarino, forma parte de una zona tampón de la $\mathrm{RBCH}$, y ha sido declarado también un Sitio Prioritario para la Conservación de la Biodiversidad por CONAMA (2002).

D. Escala local $=$ Parque Etnobotánico Omora. Sobre la imagen satelital de la cuenca del río Róbalo se señalan los límites del Parque Omora (1,044 ha). Arriba a la derecha se observa la ciudad de Puerto Williams abastecida de agua bebestible por el río Róbalo que nace en el cordón montañoso de los Dientes de Navarino y desemboca en la bahía Róbalo en el canal Beagle.

Multiple scales at which the biocultural research, education, and conservation programs associated with the Omora Ethnobotanical Park takes place.

A. International scale $=$ Subantartic Biocultural Conservation Program, coordinated by the University of North Texas (UNT), the Institute of Ecology and Biodiversity (IEB), and the Universidad de Magallanes (UMAG) (yellow stars). The circles indicate the core collaborators in the United States of North America (light blue = Institute of Ecosystem Studies, University of Connecticut, University of Georgia and the Ecological Society of America), in Mexico and Costa Rica (red = Ibero-MAB at the Instituto de Ecologia Xalapa, and the Universidad de Cooperación Internacional de Costa Rica), in South America (orange = Universidad Nacional de Colombia, Instituto Antártico Chileno, Centro Austral de Investigaciones Científicas - Ushuaia, Argentina, and Red AVINA Patagonia), in Europe (lilac = Center for Environmental Research UFZ, Leipzig in Germany, Universidad Complu- 
El descubrimiento de la importancia de la flora no vascular en la cuenca del río Róbalo ilustra cómo la investigación científica contribuye a comprender características de una cuenca subantártica, particularidad que la hace diferente de las cuencas de los Andes de Chile central donde es la flora vascular la que desempeña el papel más importante en la regulación hídrica. En base a este descubrimiento, en colaboración con el gobierno provincial y otros servicios públicos, se ha desarrollado un modelo novedoso para el manejo de una cuenca hidrográfica y la administración de recursos hídricos públicos, considerando las singularidades ecológicas de esta remota región del país y del continente. Para consolidar esta alianza público-privada establecida por el programa científico del Parque Omora e instituciones estatales, se encuentran en trámite la firma de convenios con el Ministerio de Obras Publicas-Dirección General de Aguas y con el Ministerio de Bienes Nacionales, con el objeto de asegurar estos servicios ecosistémicos (suministro de agua bebestible de alta calidad) proporcionados por la biodiversidad (especialmente la flora criptogámica subantártica) y la integridad ecosistémica de la cuenca del río Róbalo para los pobladores y la industria de la Comuna de Cabo de Hornos.

\section{I.1.2. Sitio Prioritario para la Conservación de} la Biodiversidad Subantártica

El Parque Omora, la cuenca del río Róbalo y el cordón montañoso Dientes de Navarino albergan un mosaico representativo de hábitats subantárticos de la región archipelágica del Cabo de Hornos, al sur de Tierra del Fuego. Estos hábitats incluyen los bosques más australes del mundo. Dominados por especies de Nothofagus, estos forman bosques siempreverdes de coigüe de Magallanes ( $N$. betuloides [Mirb.] Oerst) en las zonas bajas $(<100 \mathrm{~m})$, bosques mixtos (siempreverdes y deciduos) dominados por coigüe de Magallanes y lenga (Nothofagus pumilio [Poepp. et Endl.] Krasser, 1896) en altitudes intermedias $(100-250 \mathrm{~m})$ y bosques deciduos dominados por lenga y ñirre $(N$. antarctica [G. Forst.] Oerst., 1871) en las zonas altas (250-450 m; Fig. 2).

Debido a que el cerro Róbalo y los Dientes de Navarino poseen las cumbres más altas de la isla Navarino, el Parque Omora protege también el perfil altitudinal florísticamente más diverso de la costa norte de la isla (Rozzi et al. 2004, 2006b). Este perfil se extiende desde la costa (zona intermareal y submareal con sus bosques de huiro, el alga Macrocystis pyrifera [L.] C. Agardh, 1820), ascendiendo

tense de Madrid in Spain and Parco Dolomiti Bellunesi in Italy), and in Australia (green = University of Sunshine Coast).

B. National Scale = Chilean Network of Long-Term Socio-Ecological Research (LTSER) Sites coordinated by IEB. The map shows the location of the five involved universities (blue stars) and the three LTSER sites (red circles), whose locations cover an extensive latitudinal range along the Pacific coast of Chile, encompassing the whole latitudinal range of the South American temperate forests biome (golden color); from the semi-arid ecosystems in Fray Jorge to the temperate evergreen rainforests on Chiloe Island, and the sub-Antarctic ecoregion (light green) in Cape Horn. Together with gradients in precipitation, temperature, and photoperiod these sites a gradient of anthropogenic disturbance, from the rural-urban in the north to the pristine in the extreme south. The sites in Fray Jorge National Park and Omora Park are located in UNESCO-designated Biosphere Reserves, while Senda Darwin is a private reserve associated with Chiloe National Park.

C. Local-regional scale $=$ the Cape Horn Biosphere Reserve (CHBR). Map of the extreme south of South America, indicating the zoning of the CHBR. In green: core areas that correspond in their totality to the areas included in Alberto de Agostini and Cape Horn National Parks, administered by the National Forestry Corporation (CONAF). In dark pink: terrestrial buffer areas that are made up almost entirely of state lands, administered by the Ministry of National Lands and the coastal border under the control of the Ministry of Defense. In light pink: marine buffer areas located in interior waters, administered by the Ministry of Defense and the Sub-secretary of Fisheries. In dark yellow: terrestrial transition zones where we find the town of Puerto Williams and other small human settlements. In light yellow: marine transition zones that encompass the area surrounded by the marine buffer areas. Note that Omora Park on the northern coast of Navarino Island forms part of a buffer area of the CHBR, and it has also been designated as a priority site for the Preservation of Biodiversity by the National Environmental Commission (CONAMA 2002).

D. Local Scale = Omora Ethnobotanical Scale. The boundaries of Omora Park are indicated on the satellite image of the Robalo river watershed. Upper right is the town of Puerto Williams, which obtains its drinkable water from the Robalo river that flows from the adjacent mountain, Dientes de Navarino, into Robalo bay in the Beagle Channel. 
por turberas, bosques y matorrales $(0$ a $400 \mathrm{~m}$, aproximadamente) hasta la zona altoandina, que incluye formaciones de plantas en cojín y una prolífica vegetación de líquenes y musgos (400-900 m aproximadamente). En la zona altoandina, por sobre el límite arbóreo, en las cumbres del cerro Róbalo y el cordón de los Dientes de Navarino, se encuentran especies de líquenes como Usnea aurantiacoatra (Jacq), que también se registra en la península Antártica (Sancho et al. 2006). Estos descubrimientos botánicos revelan los vínculos biogeográficos entre las ecorregiones subantártica y antártica (Goffinet et al. 2006).

Para propósitos educativos y de turismo científico, el perfil altitudinal del Parque Omora y el buen estado de conservación en muchos sectores, permite que se pueda reconocer y disfrutar en terreno un hermoso y diverso mosaico de hábitats subantárticos en un área relativamente pequeña y accesible desde Puerto Williams (Ibarra et al. 2007). Además, en estos hábitats podemos encontrar especies vulnerables o en peligro a nivel nacional (e.g., el cóndor andino, Vultur gryphus Linneaus, 1758, y el carpintero magallánico, Campephilus magellanicus King, 1828), pero que en la $\mathrm{RBCH}$ son relativamente comunes (Arango et al. 2007, Ibarra et al. 2007).

Debido a su relevancia ecosistémica (cuenca hidrográfica), rica biodiversidad, aptitud para la educación formal e informal y para el turismo científico, en el año 2002 la Comisión Nacional del Medio Ambiente identificó al Parque Omora y el área aledaña de la cuenca del río Róbalo como Sitio Prioritario para la Conservación de la Biodiversidad en la Región de Magallanes y Antártica Chilena (CONAMA 2002). Esta designación fue luego reforzada por otro

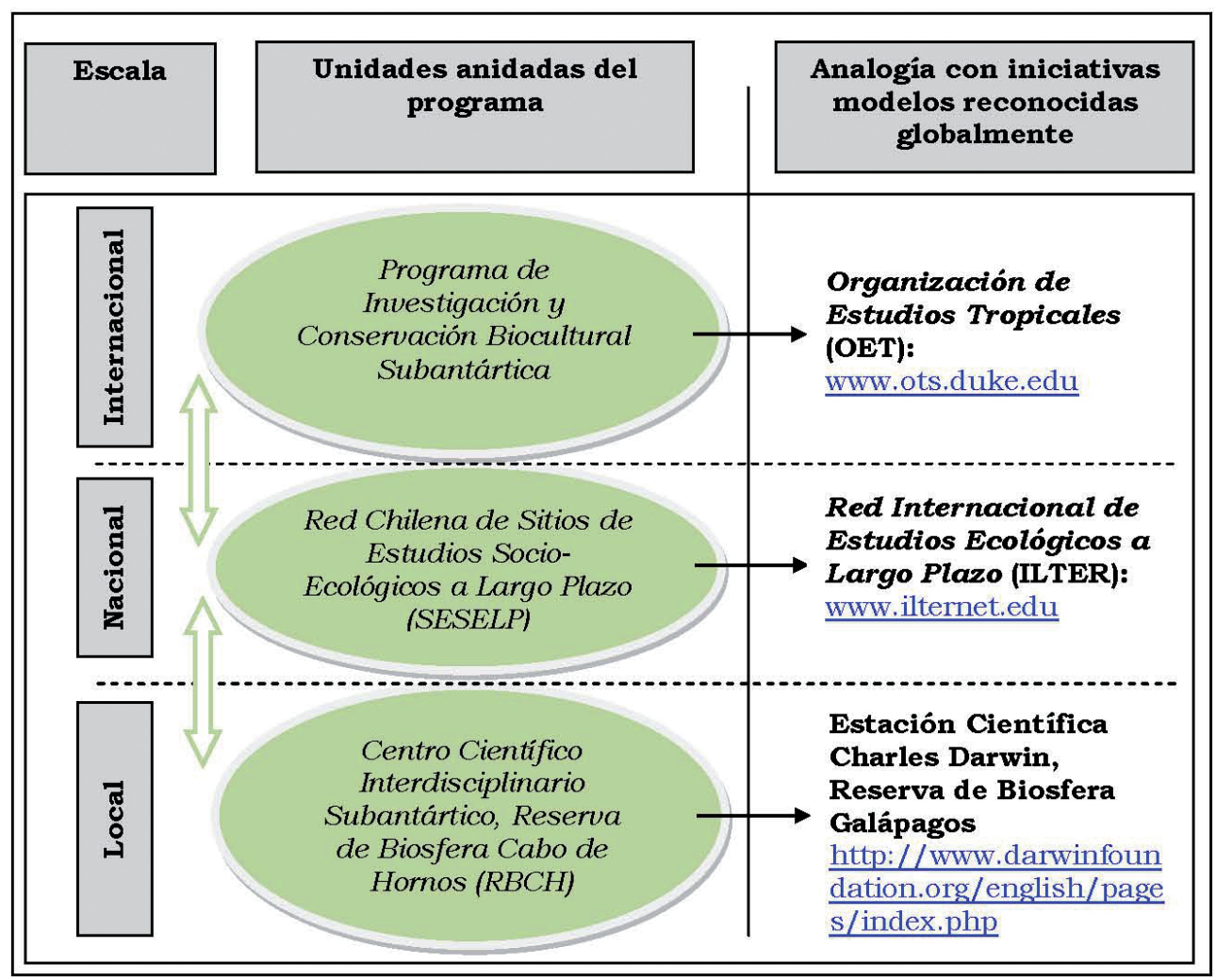

Fig. 2: Esquema de las unidades anidadas de organización que permiten articular el trabajo del programa a escalas locales, nacionales e internacionales, a través de sitios SESELP e instituciones que colaboran en red e integran diversas disciplinas relevantes para la conservación biocultural.

A schematic representation of the nested organizational units that enables the articulation of the work at local, national, and international scales, through collaborative networks of LTSER sites and institutions that bring diverse disciplines that are relevant for biocultural conservation. 
programa nacional coordinado por CONAMA: el Sendero de Chile. El Parque Omora junto al cerro Bandera forman parte de la cuenca del río Róbalo y fueron implementados el año 2003 como el tramo más austral del Sendero de Chile, que permite recorrer Chile a pie (http://www.senderodechile.cl/1310/article44617.html). Finalmente, el 2008 el Parque Omora se constituyó en un sitio cofundador de la Red Chilena de Estudios SocioEcológicos a Largo Plazo coordinada por el IEB (Anderson et al. 2008, Anderson et al. 2001). Esta red refuerza la continuidad de los programas de investigación, educación y conservación en este sitio prioritario para la conservación de la diversidad biológica subantártica.

I.1.3. Un sitio de investigación, educación y conservación biocultural en la Reserva de Biosfera Cabo de Hornos

El Parque Omora está ubicado cerca de Puerto Williams, de la Villa Ukika donde reside la mayoría de los miembros de la Comunidad Indígena Yagán, y de la Base Naval Beagle, donde residen las familias de los funcionarios de la Armada de Chile. Por esta razón, el parque ofrece un sitio ideal para explorar in situ los hábitats nativos y las distintas formas de conocer y valorar la biodiversidad subantártica con los diversos actores de las escuelas, jardines infantiles, servicios públicos, miembros de la Comunidad Yagán, personal de la Armada, otros residentes, operadores turísticos y visitantes. Estas diversas personas poseen distintos conocimientos, intereses y necesidades sociales, culturales y económicas en la biodiversidad subantártica (Berghoefer et al. 2008). Más aún, esta biodiversidad austral es en gran medida omitida por los programas de educación formal de la Región de Magallanes y Antártica Chilena (Rozzi et al. 2008b). Por lo tanto, el Parque Omora como sala de clases al aire libre llena un vacío en la educación formal e informal regional, y nacional también.

La omisión de la diversidad subantártica en los programas de educación formal no solo afecta a la diversidad biológica, sino también a la diversidad cultural. Por esta razón, en colaboración con miembros de la Comunidad Yagán, el Parque Omora ha desarrollado programas relativos al lenguaje y conocimiento ecológico yagán de la flora y fauna de Cabo de Hornos (Rozzi et al. 2003, Zárraga et al. 2005, Massardo \& Rozzi 2006). Además, hemos realizado talleres educativos con miembros de todos los grupos socioculturales de Cabo de Hornos en torno a especies carismáticas, como el pájaro carpintero (Arango et al. 2007). En primer lugar, estos trabajos permiten descubrir la riqueza de la diversidad cultural de Cabo de Hornos. Segundo, las experiencias de campo ayudan a interrelacionar esta diversidad cultural con el pájaro carpintero, otras aves y seres vivos que cohabitan en los paisajes de Cabo de Hornos. Tercero, esta interrelación entre ambas diversidades permite a los participantes de los talleres esbozar una síntesis para una comprensión de la diversidad biocultural subantártica. Finalmente, esta comprensión permite incorporar las singularidades de la diversidad biocultural subantártica en los programas regionales de educación, políticas y toma de decisiones ambientales que son relevantes para el bienestar de los diversos cohabitantes y para la conservación de esta diversidad biocultural.

Para la continuidad de esta experiencia, el Parque Omora ha sido clave como sitio de campo para desarrollar actividades de investigación, educación y conservación con el Programa de Magíster en Ciencias con Mención en "Conservación y Manejo de Recursos Naturales Subantárticos" de la Universidad de Magallanes (UMAG). Este ha constituido el primer programa de postgrado en la región de la Patagonia de Argentina y Chile (http://www.umag.cl/recursosnaturales/magister). Tal como el programa del Parque Omora, el currículum de este postgrado de la UMAG enfatiza la importancia de: i) las experiencias de campo, ii) la historia natural, iii) la interrelación entre la diversidad biológica y cultural, iv) la interrelación de las artes, la filosofía ambiental y las ciencias ecológicas, v) la integración interdisciplinaria en prácticas de trabajo en educación, toma de decisiones ambientales, manejo de ecosistemas, ecoturismo y conservación biocultural, y vi) los valores éticos, intrínseco e instrumental, de la existencia de esta diversidad biocultural y de los beneficios que ella conlleva para la sociedad. 
Los cursos de postgrado en terreno, llevados a cabo en el bosque, turberas, hábitats costeros y altoandinos del Parque Omora, han permitido que filósofos y científicos puedan explorar la forma de integrar las ciencias ambientales, la ética ambiental y las artes con el fin de desarrollar investigación interdisciplinaria y métodos educativos diseñados para entender y conservar la diversidad biocultural austral (véase Estévez 2010). El programa de postgrado de la UMAG incluye experiencias en terreno en prácticas formales e informales, con instituciones privadas y públicas, así como también participación en proyectos de investigación socioecológica a largo plazo en la $\mathrm{RBCH}$. La reciente colaboración del Parque Omora con la Escuela de Educación Parvularia de la Universidad de Magallanes, ha abierto además un área de interacciones interdisciplinarias enriquecedoras para las alumnas y el plantel de docentes de educación preescolar de la región, que ha generado programas de educación ecológica y ética ambiental para jardines infantiles a nivel nacional con la creación de los Clubes Explorines de CONICYT. De esta manera el parque funciona como un tipo de laboratorio natural y un centro de investigación interdisciplinaria para la $\mathrm{RBCH}$, que depende vitalmente de la continua actividad llevada a cabo por los estudiantes de postgrado de la UMAG y otros centros académicos chilenos y extranjeros.

\section{I.2. Escala nacional: Red Chilena de Sitios de Estudios Socio-Ecológicos a Largo Plazo}

En el año 2008 el Parque Omora cofundó la primera Red Chilena SESELP (Anderson et al. 2008) con financiamiento del Programa de Financiamiento Basal de CONICYT y la Iniciativa Científica Milenio de MIDEPLAN. La meta inicial de la red (2008-2011) es consolidar los programas de investigación y educación que actualmente existen entre los tres sitios fundadores: Sitio Experimental Fray Jorge ( $30^{\circ}$ S) (ver Gutiérrez et al. 2010), la Estación Biológica Senda Darwin ( $42^{\circ} \mathrm{S}$ ) (ver Carmona et al. 2010) y el Parque Omora (55 S). En una segunda fase (2011-2013), la iniciativa proyecta incluir nuevos sitios de estudio, especialmente en biomasa poco representados, como los
Andes de Chile central y el desierto de Atacama. Esta red, coordinada por el IEB, provee una plataforma única para desarrollar investigación interdisciplinaria sobre biodiversidad, procesos ecosistémicos y cambio ambiental global, y sobre las interrelaciones de estos con la sociedad a través de un programa de investigación socioecológica, teórica y aplicada. La fortaleza de esta plataforma deriva por un lado en la calidad de los grupos de investigadores e instituciones asociadas al IEB, que incluyen a la Universidad de Chile, P. Universidad Católica, Universidad de la Serena, Universidad de Concepción y Universidad de Magallanes. Por otro lado, estas instituciones y los tres sitios de estudio cubren un área geográfica que: i) se extiende sobre el gradiente latitudinal más amplio de bosques templados en el hemisferio Sur, ii) este gradiente incluye marcados cambios en precipitación, temperatura y fotoperíodo, iii) corresponde al área del mundo con la menor contaminación atmosférica por depositación (Galloway et al. 2004). Además, los programas de los tres sitios consolidan 20 años de investigación a largo plazo e iniciativas pioneras en la integración de disciplinas académicas, y con la academia y la sociedad (Armesto 1990, 1995, Anderson et al. 2008).

La red tiene como misión fundamental desarrollar investigación a largo plazo, reforzar e implementar cursos de campo, internacionales e interdisciplinarios, se integra en iniciativas nacionales e internacionales que dan relevancia a la investigación en contextos sociales, regionales y globales. Respecto a los programas de investigación de esta Red Chilena SESELP coordinada por el IEB, se ha establecido un registro de variables biofísicas para caracterizar procesos ecosistémicos y climáticos con metodologías comparables entre los tres sitios, y con la Red Internacional de Sitios de Estudios Ecológicos a Largo Plazo (ILTER, International Long-Term Ecological Research por su sigla en inglés). Las bases de datos serán utilizadas para realizar experimentos a largo plazo y evaluar las respuestas de la biota y los ecosistemas frente al cambio climático global en distintas latitudes.

En el ámbito de investigaciones ecológicas, el Parque Omora se beneficiará 
significativamente de la extensa experiencia de los equipos de investigadores de la Estación Biológica Senda Darwin y Sitio Experimental Fray Jorge, y de los programas del IEB y de sus instituciones asociadas. A su vez, algunas contribuciones del equipo de investigación del Parque Omora en el ámbito de la ecología incluyen: i) el programa de anillamiento mensual de aves paseriformes de bosques templados más largo del sur de Sudamérica; ii) el programa de investigaciones y manejo de mamíferos exóticos invasores, desarrollado bajo la autorización y en colaboración con el Servicio Agrícola y Ganadero y la Oficina Nacional de Anillamiento; iii) inventarios de diversidad y estudios de historias de vida de la fauna de invertebrados dulceacuícolas; iv) estudios de biodiversidad y usos potenciales de macroalgas subantárticas; v) estudios de diversidad y ecología de briófitas y líquenes.

Dentro de la Red SESELP coordinada por el IEB, el Parque Omora tiene la misión específica de desarrollar nuevas metodologías y enfoques para la educación y la conservación biocultural, y de contribuir a la integración de las dimensiones sociales y ecológicas en la investigación teórica y aplicada. Es más, el programa de Financiamiento Basal para Centros Científicos y Tecnológicos de Excelencia (CONICYT) demanda explícitamente que los centros de excelencia contribuyan a incrementar el desarrollo social de Chile y la economía competitiva. En este contexto, el Parque Omora desarrolla programas de turismo científico que incluyen investigación aplicada, formación de guías de turismo, publicación de materiales e implementación de infraestructura para el ecoturismo. Un programa particular en esta dirección ha sido la identificación e implementación de especies y hábitats carismáticos, tales como el pájaro carpintero gigante (C. magellanicus King, 1828) o el colibrí (Sephanoides sephaniodes Lesson, 1827), llamado omora en lengua yagán (Arango et al. 2007). Las especies carismáticas han mostrado ser efectivas para la conservación y las iniciativas de ecoturismo, y el Parque Omora está innovando con la propuesta de líquenes, musgos e insectos carismáticos, a la vez que está contribuyendo a que cada uno de los tres sitios de estudio tenga sus propias especies carismáticas. Una meta de largo-plazo es el desarrollo de metodologías para integrar la filosofía ambiental en la teoría y praxis de la investigación, educación y conservación biocultural. El desarrollo de esta meta se basa en una alianza con centros internacionales, como la Universidad de North Texas (UNT), que poseen una vasta experiencia en filosofía y ética ambiental, como también en educación y ciencias ambientales.

\section{I.3. Escala internacional: El Programa de Con- servación Biocultural Subantártica}

Como se afirmó en la introducción, dos grandes desafíos que el programa del Parque Omora se ha propuesto para lograr que la investigación ecológica tenga una relevancia social en el contexto de cambio ambiental global, son: i) la articulación de programas de investigación a escalas locales y nacionales con escalas globales, y ii) la integración de las ciencias ecológicas y la ética ambiental. Para lograr estos dos objetivos, la Universidad de North Texas (UNT) ha constituido un colaborador ideal por dos razones. Primero, alberga el Centro de Filosofía Ambiental (Center for Environmental Philosophy, CEP, http://www.cep.unt.edu) que en 1978 fundó la revista Ética Ambiental (Environmental Ethics), la primera y más importante a nivel mundial en la joven subdisciplina de la ética ambiental que emergió en la década de los 1970 (Hargrove 1988). A fines de la década de los 1990, iniciamos una colaboración con CEP que introdujo una serie de artículos sobre ética ambiental, conservación y educación en Chile (e.g., Hargrove 1997, Oelchlaeger \& Rozzi 1998), y también estimuló la creación de capítulos regionales (incluyendo una sección sudamericana) dentro de la Sociedad Internacional de Ética Ambiental en 1998 (http://www.cep.unt.edu/ISEE.html). La segunda razón es que la UNT ha integrado las ciencias ambientales y la ética ambiental en programas de investigación y educación de pre y postgrado, y recientemente ha priorizado los objetivos de interdisciplinariedad, internacionalización y diversidad (UNT 2008). En este contexto, a inicios de la década de los 2000, la Universidad de Magallanes (UMAG) en asociación con el Instituto de Ecología y Biodiversidad (IEB), iniciaron colaboraciones 
con UNT, y el año 2007 se creó formalmente el Programa de Conservación Biocultural Subantártica (http://www.chile.unt.edu y http://www.umag.cl). Este programa posee oficinas en la UMAG Punta Arenas y Puerto Williams en Chile, y en la UNT en Denton, Texas, EE.UU. Las instituciones coordinadoras de cada país financian su personal y las oficinas, y para la consolidación académica del programa, UNT y UMAG están contratando nuevos profesionales para desarrollar proyectos colaborativos entre investigadores de ambas instituciones y del IEB y otros centros académicos asociados (Figs. 1A y 1B).

El programa es actualmente coordinado por tres instituciones chilenas -IEB, UMAG y Fundación Omora (http://www.ieb-chile.cl, http://www.umag.cl, http://www.omora.org)y por tres instituciones estadounidenses, UNT, CEP y la organización no gubernamental OSARA (Omora Sub-Antarctic Research Alliance; http://www.unt.edu, http:// www.osara.org; ver Anderson et al. 2008). En algunos aspectos este consorcio de seis instituciones funciona de manera similar a la Organización de Estudios Tropicales (OET) que tiene sedes en la Universidad de Duke y en la Ciudad de la Investigación de la Universidad de Costa Rica en San José (http:// www.ots.duke.edu). Fundada en la década de los años 1960, la OET posee tres estaciones biológicas en Costa Rica (entre ellas La Selva es la mejor conocida) que han sido fundamentales para el descubrimiento de la alta biodiversidad en ecosistemas tropicales, como también para comunicar la importancia planetaria de estos ecosistemas. La OET consiste hoy en una red de socios formada por 60 universidades e instituciones estadounidenses, y también latinoamericanas (Costa Rica, México, Perú), Sudáfrica y Australia.

La OET ha representado un modelo para el desarrollo de nuestro Programa de Conservación Biocultural Subantártica, aunque este último posee mayor simetría entre las instituciones chilenas y las estadounidenses. Además, nuestro programa se distingue de la OET en tres aspectos fundamentales: i) respecto al área geográfica, que se centra en latitudes altas que han recibido menor atención para la conservación comparado con las latitudes tropicales; ii) respecto a la metodología de los cursos, porque en ellos participan conjuntamente investigadores y estudiantes chilenos, latinoamericanos, estadounidenses y de otras regiones del mundo, mientras que la OET ofrece cursos separados para estadounidenses y latinoamericanos; iii) respecto al foco temático, la OET enfatiza la investigación ecológica incorporando recientemente variables socioecológicas (principalmente socioeconómicas), en cambio nuestros cursos e investigación enfatizan la integración de las ciencias ecológicas, la ética ambiental y las artes en la teoría y práctica del ecoturismo, la educación y la conservación biocultural. Estas interesantes complementariedades entre la OET y el Programa de Conservación Biocultural Subantártica han estimulado una fructífera colaboración entre ambos programas.

Con el objetivo de promover un diálogo entre ecólogos, filósofos y otros pensadores ambientales latinoamericanos y estadounidenses, el Programa de Conservación Biocultural Subantártica ha inaugurado una serie de publicaciones bilingües (español e inglés) de filosofía ambiental, ecología y conservación. Esta serie ha incluido los artículos ocasionales de la Sociedad Internacional de Ética Ambiental (http://www.cep.unt.edu/iseepapers/ index.htm), y números especiales de Environmental Ethics (2008, vol 30 (3) y 2011, en preparación), complementados con este Tema Especial de la Revista Chilena de Historia Natural (2010 vol 83 (1)). Además, se ha creado una línea editorial conjunta entre UNT Press y Ediciones UMAG que incluye tres series de libros: i) ediciones y traducciones anotadas de textos fundamentales de filosofía ambiental latinoamericana y anglosajona, del español al inglés, y viceversa; ii) guías de campo sobre la diversidad biocultural subantártica y conservación para educadores, operadores turísticos y público general; iii) libros académicos basados en investigación original sobre ecología, historia natural, diversidad y conservación biocultural de la ecorregión templada y subantártica de Sudamérica austral.

Esta serie de publicaciones y el programa en general procuran promover la teoría y 
práctica de la conservación biocultural y su implementación en los programas de investigación a largo plazo internacional, enfatizando la interfase entre las ciencias ecológicas y la ética ambiental (véase Estévez et al. 2010). La red de colaboraciones académicas en la investigación ecológica a largo plazo está embebida en redes internacionales de jardines botánicos (e.g., Red de Jardines Etnobotánicos Hermanos Latinoamericanos), de participación $\mathrm{y}$ liderazgo comunitario (e.g., AVINA), de educación (e.g., Enseñanza de la Ecología en el Patio de la Escuela) que promueven la sustentabilidad.

\section{DOS INICIATIVAS INTERNACIONALES INFLUYENTES}

Entre las redes internacionales que promueven la sustentabilidad ecológica y social, dos han sido especialmente influyentes para la definición de metodologías de los programas de investigación, educación y conservación biocultural del Parque Omora: i) la Red de Reservas de Biosfera del Programa El Hombre y la Biosfera, de la Organización de las Naciones Unidas para la Educación, la Ciencia y la Cultura (UNESCO del inglés United Nations Educational, Scientific and Cultural Organization), y ii) la Iniciativa para una

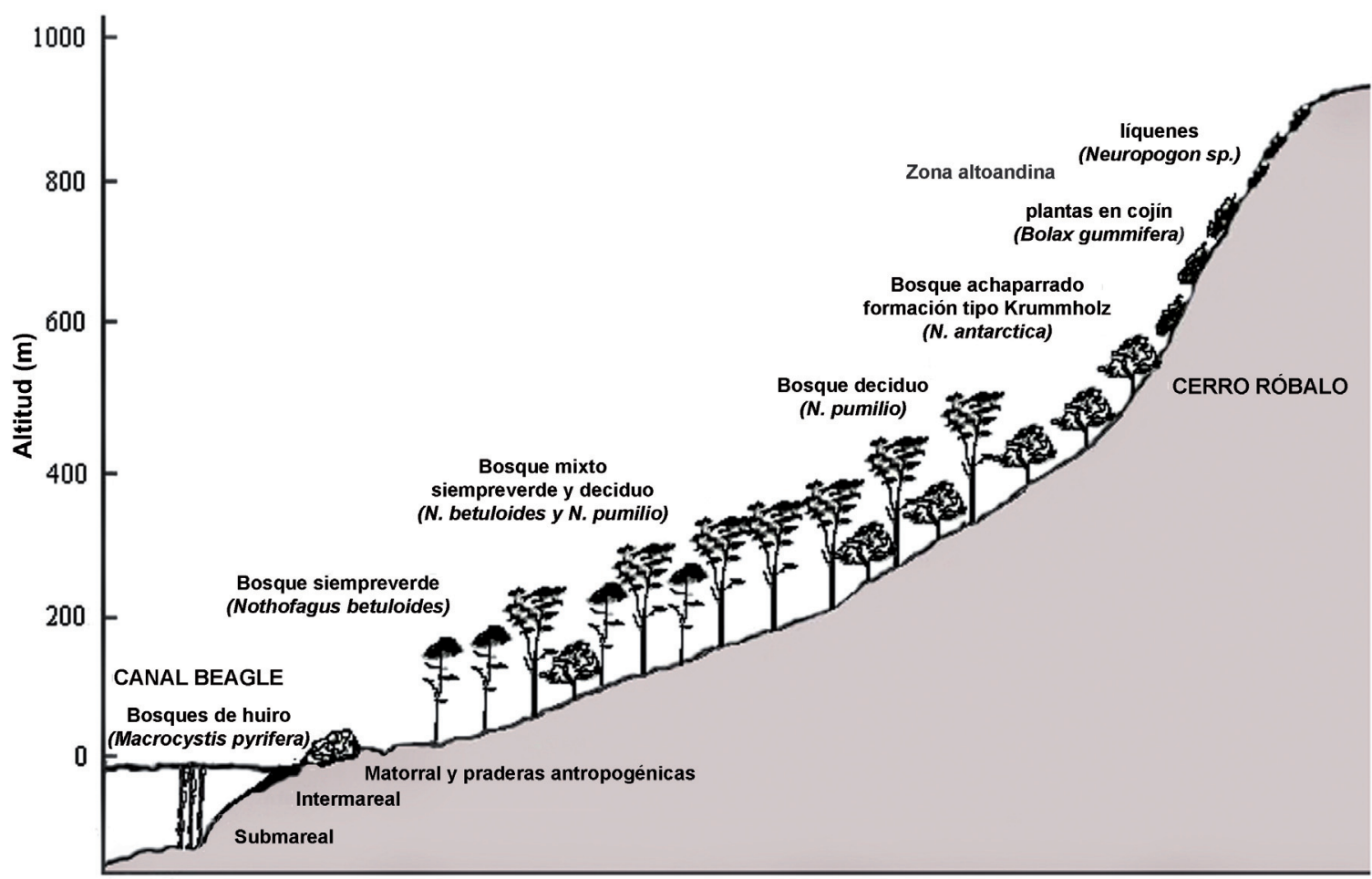

Fig. 3: El Parque Omora se extiende desde el canal Beagle hasta los $920 \mathrm{~m}$ de altitud en la cima del cerro Róbalo. Este gradiente altitudinal incluye los tipos de hábitats característicos de la región del Cabo de Hornos. Desde la línea de playa hacia arriba estos hábitats son: bosques de huiro de Macrocytis pyrifera, bosques siempreverdes dominados por Nothofagus betuloides; bosque mixto siempreverde-deciduo dominado por $N$. betuloides y $N$. pumilio; bosques deciduos dominados por $N$. pumilio y $N$. antarctica; zona altoandina dominada por plantas en cojín en la parte más baja, e.g., Bolax gummifera; y por líquenes como Neuropogon sp. en las cumbres más altas.

Omora Park extends $920 \mathrm{~m}$ from the Beagle Channel to the summit of Robalo Mountain. This altitudinal gradient includes the characteristic habitat types of the Cape Horn region. From the shoreline upwards these habitats are: kelp forests of Macrocytis pyrifera, evergreen forests dominated by Nothofagus betuloides; mixed evergreen-deciduous forests dominated by $N$. betuloides and $N$. pumilio; deciduous forests dominated by $N$. pumilio and N. antarctica; alpine tundra dominated at lower levels by cushion plants, e.g., Bolax gummifera; and at upper levels by lichens (Neuropogon sp.). 
Biosfera Sustentable (SBI, Sustainable Biosphere Initiative) de la Sociedad de Ecología de los Estados Unidos de Norteamérica (ESA, Ecological Society of America).

\section{II.1. Programa UNESCO "El Hombre y La Bios- fera" y la creación de la Reserva de Biosfera Cabo de Hornos}

El Programa El Hombre y la Biosfera (MaB, del inglés Man and Biosphere) de UNESCO se inició en 1970 con el fin de superar aproximaciones preservacionistas a la conservación biológica que excluyen a los humanos de áreas protegidas, con el objeto de promover, en cambio, perspectivas que reconcilian las necesidades sociales, culturales, recreativas y ecológicas (Guevara \& Laborde 2008). Un elemento fundamental del método del programa $\mathrm{MaB}$ fue el establecimiento de una red internacional de reservas de biosfera. Esta red ha llegado a incluir un mosaico de sitios únicos en el mundo que representan a los principales ecosistemas del planeta, protegidos a través del desarrollo de programas de investigación, monitoreo, educación, conservación y desarrollo sustentable. Hoy el Programa MaB tiene como objetivos centrales: i) minimizar las pérdidas de diversidad biológica, ii) generar conciencia acerca de la interdependencia de la diversidad biológica y cultural, y iii) promover la sustentabilidad ambiental a través de la Red Mundial de Reservas de la Biosfera.

Durante los 1990, un diverso grupo de académicos y otras personas asociadas con la creación del Parque Etnobotánico Omora advertimos los notables paralelos de los objetivos del Programa MaB y nuestra aproximación biocultural a la investigación, educación y conservación en el archipiélago subantártico de Magallanes. Más aún, en 1996 el Programa $\mathrm{MaB}$ acordó la Estrategia de Sevilla (UNESCO 1996) donde las reservas de biosfera deben lograr tres funciones complementarias: a) conservación de la biodiversidad, b) desarrollo económico humano sustentable, y c) apoyo logístico para investigación, educación, capacitación y monitoreo.

Dada esta coincidencia de objetivos y en estrecha colaboración con el Gobierno Regional, el equipo de investigadores del
Parque Omora inició el año 2001 un proceso para postular ante UNESCO a Cabo de Hornos como un sitio único en el mundo que merecía la nominación de reserva de biosfera. El proceso de postulación fue liderado políticamente por el Gobierno de la Provincia Antártica Chilena, la Corporación Nacional Forestal (CONAF), la Comisión Nacional del Medio Ambiente (CONAMA), el Ministerio de Bienes Nacionales, la Armada de Chile y la I. Municipalidad de Navarino, que como parte del proceso de construcción de identidad cambió su nombre al de Comuna de Cabo de Hornos en el año 2002 (Barros \& Harcha 2004). En este proceso, el equipo de trabajo del Parque Omora asumió un papel de equipo técnico-científico para la preparación del documento de postulación que fue aprobado durante la reunión anual del Consejo Internacional de Coordinación del Programa MaB de UNESCO el 27 de junio de 2005, fecha de la creación oficial de la Reserva de Biosfera Cabo de Hornos (RBCH; Rozzi et al. 2006b).

Durante el proceso de cinco años de preparación de postulación de la $\mathrm{RBCH}$, los investigadores del Parque Omora trabajaron con las autoridades procurando: i) la mayor participación posible de la comunidad local, especialmente de la comunidad educativa y la Comunidad Indígena Yagán; ii) la colaboración interinstitucional, especialmente con la Corporación de Fomento de la Producción (CORFO), el Servicio Nacional de Turismo (SERNATUR), el Servicio Agrícola y Ganadero (SAG), la Corporación Nacional de Desarrollo Indígena (CONADI), el Servicio Nacional de Pesca (SERNAPESCA) y la Subsecretaría de Marina del Ministerio de Defensa; iii) la asociación con centros de investigación nacionales (e.g., Instituto Antártico Chileno, Museo Nacional de Historia Natural) e internacionales (véase Fig. 1A). Este trabajo interinstitucional continuo generó tres procesos (y productos) coherentes con o exigidos por el Programa MaB: 1) definición de la zonificación de la $\mathrm{RBCH}, 2$ ) control de especies de mamíferos exóticos invasores para prevenir la degradación ambiental en la $\mathrm{RBCH}$, y 3) desarrollo de temáticas, circuitos y actividades innovadoras para el turismo científico subantártico, como una contribución a la sustentabilidad económica y ambiental en la $\mathrm{RBCH}$. 
II.1.1. Planificación territorial: zonificación de la Reserva de Biosfera Cabo de Hornos ( $\mathrm{RBCH})$

Delimitar el territorio de la $\mathrm{RBCH}$ requirió una compleja integración de investigación ecológica, histórica, social, política y económica. Los resultados de esta investigación proveyeron información de línea de base para intensos procesos de discusión y deliberación para definir la zonificación de la $\mathrm{RBCH}$. Las zonas propuestas abarcaron toda la Comuna Cabo de Hornos en la Provincia Antártica Chilena y el sector sur de la Comuna de Timaukel, en la Provincia Tierra del Fuego. Las áreas marinas y terrestres incluían casi exclusivamente territorios fiscales sujetos a la administración y regulación de diversos servicios públicos comunales, provinciales, regionales y nacionales. Los tres tipos de zonas básicas que constituyen una reserva de biosfera y que estuvieron sujetas a discusión son: (i) áreas núcleo (zonas de preservación estricta), (ii) zonas tampón (área donde se permiten actividades de bajo impacto, tales como ecoturismo y pesca artesanal), y (iii) zonas de transición (área que permite actividades de desarrollo, como infraestructura para el turismo y otras actividades económicas sustentables).

El modelo de reserva de biosfera demanda que las áreas núcleo posean un grado de protección legal. Por lo tanto, las únicas zonas que calificaban para áreas núcleo eran los parques nacionales regulados por la Ley 18,362 de Áreas Silvestres Protegidas del Estado. Tanto los asesores de UNESCO como los investigadores del Parque Omora recomendaron incluir los parques nacionales Cabo de Hornos (44,000 ha) y Alberto de Agostini (1,400,000 ha) como áreas núcleo. Esta recomendación fue acogida por las autoridades y otros actores (Fig. 1C). En cambio, respecto a la zonas tampón y transición el debate entre la comunidad local, sectores públicos y la industria privada fue intenso, especialmente respecto a las áreas geográficas donde se permitiría salmonicultura y construcción de infraestructura turística. Como resultado se definieron áreas de transición que fomentarían el desarrollo de la necesaria infraestructura turística (e.g., hoteles, aeropuertos, facilidades portuarias) y también un desarrollo industrial, siguiendo las mejores prácticas ambientales y sujetos a una estricta normativa ambiental (Barros \& Harcha 2004). En estas zonas de transición se proveen infraestructura y servicios esenciales para las actividades de turismo sustentable, sin impactar las zonas núcleo ni tampón. Por ejemplo, en las zonas de transición los visitantes pueden embarcarse en yates, lanchas pesqueras $\mathrm{u}$ otro tipo de embarcaciones adaptadas al turismo y navegar a través de zonas prístinas (áreas núcleo) y visitar zonas que permiten actividades de bajo impacto en las zonas tampón. Esta zonificación favorece (a) la economía local, (b) la calidad de la experiencia del visitante que recorre Cabo de Hornos navegando, esto es, como se ha recorrido desde tiempos ancestrales, (c) la economía nacional y global porque se ofrece una actividad única, y (d) la conservación biocultural porque se mantienen la pristinidad del área y las tradiciones culturales, como la navegación y la pesca artesanal. A pesar de esta zonificación favorable para el conjunto de los actores, y que el mapa de zonificación expresa el consenso logrado entre autoridades de Gobierno, la mayoría de los dueños o concesionarios de tierras y el comité científico (Fig. 1C), el debate sobre la planificación territorial ha continuado después de que UNESCO designara la RBCH en el 2005. Por ejemplo, inversionistas de otras regiones y compañías de turismo nacionales 0 extranjeras han presentado reiteradas propuestas para construir infraestructura de alojamiento dentro de las áreas núcleo. Tal infraestructura eliminaría los cuatro tipos de beneficios: económicos, sociales, culturales y ecológicos, alcanzados con la zonificación actual.

En este contexto, los sitios de estudios socioecológicos a largo plazo proveen una estrategia apropiada para satisfacer demandas de información y capacidades técnicas tanto locales como regionales. Procesos políticos, tales como la definición de la zonificación de la $\mathrm{RBCH}$, no solo requieren una entrega de informes técnicos e información científica al inicio del proceso, sino que también demandan de un equipo técnico-científico capaz y disponible para interactuar continuamente con las autoridades y diversos actores sociales. Por esta razón, los investigadores del Parque Omora han creado programas de investigación, educación y conservación a largo plazo que permiten participar 
continuamente, ofreciendo los mejores criterios técnicos e información científica disponible en debates tales como los de zonificación de la $\mathrm{RBCH}$, con el fin mantener y adaptar prácticas económica y ambientalmente sustentables en escenarios política y ecológicamente cambiantes (Rozzi et al. 2007).

II.1.2. Catastro y manejo de especies exóticas invasoras

Una de las principales amenazas biológicas para la preservación de la biodiversidad en el archipiélago de Cabo de Hornos corresponde a la rápida expansión de mamíferos exóticos invasores, como el castor norteamericano (Castor canadensis Kuhl, 1820) y la rata almizclera (Ondatra zibethicus L., 1766), que llegaron a la isla Navarino desde Tierra del Fuego en la década de los 1950 y 1960 (Anderson et al. 2006). Más recientemente, en el año 2002, los investigadores del Parque Omora detectaron la llegada y rápida diseminación del visón norteamericano (Neovison vison Schreber, 1777) (Rozzi y Sherriffs 2003). Este último, voraz depredador, ha diezmado drásticamente las poblaciones de aves endémicas, tales como el pato motor (Tachyeres pteneres Forster, 1844) y la caranca (Cloephaga hybrida Molina, 1782), ambas especies que nidifican en el suelo y que evolucionaron con muy baja presión de mamíferos depredadores nativos (Ibarra 2008, Ibarra et al. 2009, Schüttler 2009, Schüttler et al. 2008, 2009).

En el caso del castor, su impacto socioeconómico negativo quedó de manifiesto para las autoridades locales durante un período de intensas precipitaciones el año 2002. La serie de castoreras y diques construidos por estos animales desde el nacimiento hasta la desembocadura de los ríos, no resistieron las altas lluvias y provocaron avalanchas amplificadas por un "efecto dominó" que destruyeron los puentes en la costa norte de la isla Navarino. El alto costo económico de reconstruir esta infraestructura dejó en claro a las autoridades de gobierno que estas especies de mamíferos exóticos representan un costo negativo no solo en términos ecológicos, sino también económicos.

Los animales domésticos asilvestrados, tales como perros, gatos y cerdos, también representan un grave problema para la integridad ecológica, las actividades económicas y el patrimonio cultural en isla Navarino (Anderson et al. 2006). Por ejemplo, los perros constituyen una grave amenaza para la pequeña población de guanaco (Lama guanicoe Mueller, 1776) remanente en la isla Navarino. Los perros también han provocado pérdidas económicas puesto que han atacado y diezmado planteles completos de ganado ovino y vacuno de los ganaderos en esta isla. Los cerdos baguales han tenido repercusiones históricas y culturales irreparables: han destruido cientos de sitios arqueológicos milenarios. Conchales, talleres líticos y enterramientos del pueblo yagán han sido devastados por estos animales en las costas norte y oeste de la isla Navarino (La Prensa Austral 2009a, 2009b).

Los hallazgos científicos realizados por el equipo científico del Parque Omora desde el año 2000, alertaron a las autoridades y a la comunidad sobre las amenazas que conllevan las especies de mamíferos exóticos invasores a través de sus impactos ecológicos, sociales y culturales. De esta manera, la investigación y monitoreo de estas especies estimuló un trabajo colaborativo entre los investigadores del Parque Omora, el Gobierno de la Provincia Antártica Chilena y el Servicio Agrícola y Ganadero (SAG) para formular e implementar un programa de detección, evaluación y control de especies exóticas dañinas, que luego se amplió a toda la Región de Magallanes y Antártica Chilena el año 2004. El establecimiento de este programa de control de invasoras en la región, con especial énfasis en la $\mathrm{RBCH}$, sirve para ilustrar la relevancia política y económica que tienen los sitios de investigación socioecológica a largo plazo, tales como el Parque Omora.

El programa del Parque Omora enfatiza colaboraciones interdisciplinarias $\mathrm{e}$ interinstitucionales in situ que permiten detectar problemas socioecológicos y crear conciencia pública sobre ellos (Rozzi et al. 2006a). Bajo esta aproximación metodológica, los científicos y estudiantes de postgrado deben estar preparados y disponibles para colaborar con las autoridades y la comunidad. Los programas a largo plazo en sitios SESELP permiten no solo abordar el diagnóstico y difusión de los problemas socioecológicos, 
sino también trabajar colaborativamente para concebir soluciones potenciales y lograr concesos políticos y económicos necesarios para implementar las soluciones propuestas, como ilustramos para el caso del desarrollo del programa de control de especies exóticas invasoras en la RBCH y Región de Magallanes y Antártica Chilena.

\section{II.1.3. Turismo científico y ecoturismo subantártico}

El actual Plan de Desarrollo Regional de Magallanes y Antártica Chilena define al turismo como una de las cinco primeras prioridades para el desarrollo económico. Entre las actividades de turismo, el turismo de naturaleza representa la principal atracción para los visitantes a la región (Chacón 2002, García 2004). La región subantártica de Magallanes, la Reserva de Biosfera Cabo de Hornos y la Península Antártica de Chile representan uno de los últimos destinos "salvajes" para el ciudadano global, cada vez más urbanizado, industrializado y homogeneizado. Esto se refleja en el creciente número de visitantes extranjeros registrados en la Región de Magallanes y Antártica Chilena y en la ciudad de Puerto Williams (Fig. 4). Durante la última década, el número de turistas extranjeros se ha duplicado en la región y ha crecido en más de un orden de magnitud en Puerto Williams. El aumento explosivo del número de visitantes extranjeros a Puerto Williams se debe en parte a la apertura del paso fronterizo entre esta ciudad chilena ubicada en la ribera sur del canal Beagle y la ciudad argentina de Ushuaia, ubicada en la ribera norte del canal; Ushuaia recibe más de 300,000 turistas extranjeros por año, quienes desde el 2003 tienen la oportunidad de visitar las áreas chilenas cruzando directamente el canal Beagle.

Considerando que el número de visitas a Cabo de Hornos está creciendo exponencialmente, la prevención de impactos negativos generados por el turismo es crítico para evitar efectos perjudiciales sobre la diversidad biológica y cultural (cfr. Fennel \& Ebert 2004). Planeado y manejado de un modo adecuado, el ecoturismo puede ser una "mina de oro" a largo plazo para la región, que podría contrastar con los anteriores ciclos económicos de corta duración basados en actividades extractivas no sustentables, tales como la caza de ballenas y la fiebre del oro en el siglo XIX o la explotación del petróleo a fines del siglo XX (Barros \& Harcha 2004). Por esta razón, los investigadores del Parque Omora han colaborado con el Gobierno Regional y el Servicio Nacional de Turismo en definir criterios para el turismo de intereses especiales que contribuyan a la conservación y valoración de las singularidades de la diversidad biocultural subantártica. Específicamente, estos investigadores han contribuido al desarrollo del turismo sustentable en la Reserva de Biosfera Cabo de Hornos a través de tres formas esenciales:

i. El Parque Etnobotánico Omora se ha constituido en un sitio de atracción para el turismo científico. En este sitio de estudios socioecológicos a largo plazo los visitantes son guiados por estudiantes de postgrado, o por guías locales especializados, quienes les ayudan a descubrir la belleza y diversidad de invertebrados dulceacuícolas y marinos en las aguas más puras del planeta (Ojeda et al. 2010).

ii. Los investigadores y estudiantes de postgrado han creado nuevas temáticas $\mathrm{y}$ actividades que diversifican la oferta de turismo científico en Cabo de Hornos y la península Antártica, a través de prácticas tales como el "turismo con lupa" que permiten a los visitantes apreciar y disfrutar la importancia ecológica de los coloridos líquenes que crecen en los bosques, tundra e intermareal subantártico y antártico (Rozzi 2005, Goffinet et al. 2006).

iii. En asociación con el Programa de Magíster en Ciencias de la UMAG, el Liceo de Puerto Williams ha establecido un programa de formación de guías especializados en turismo científico subantártico con sólida educación en ecología, ética ambiental, diversidad, y conservación biocultural (Rozzi et al. 2006b).

Estas contribuciones al turismo sustentable ilustran nuevamente la importancia de sitios SESELP con grupos de investigadores y estudiantes de postgrado preparados y disponibles para interactuar más allá de su círculo de colegas científicos. Este trabajo in situ no puede ser reemplazado solo por la entrega de publicaciones científicas o informes 
técnicos. El trabajo en el largo plazo permite desarrollar dinámicas de educación participativa que ofrecen una manera efectiva de comunicar y compartir los resultados de la investigación científica de una manera que complementa las publicaciones, y a la vez se integra dialógicamente con los escenarios cambiantes del mercado (e. g., el turismo), las necesidades de los habitantes y los nuevos descubrimientos científicos. Estas son características esenciales de los objetivos del Programa MaB de UNESCO, y la aproximación del programa del Parque Omora enfatiza una metodología transdisciplinaria de largo plazo (sensu Hirsh-Handom et al. 2008), es decir, integrando no solo disciplinas sino también diversas instituciones y actores.

\section{II.2. Una adaptación chilena de la "Iniciativa para una Biosfera Sustentable" (SBI)}

En 1988 la Sociedad de Ecología de Estados Unidos de Norteamérica (ESA por su sigla en inglés) generó la Iniciativa para una Biosfera

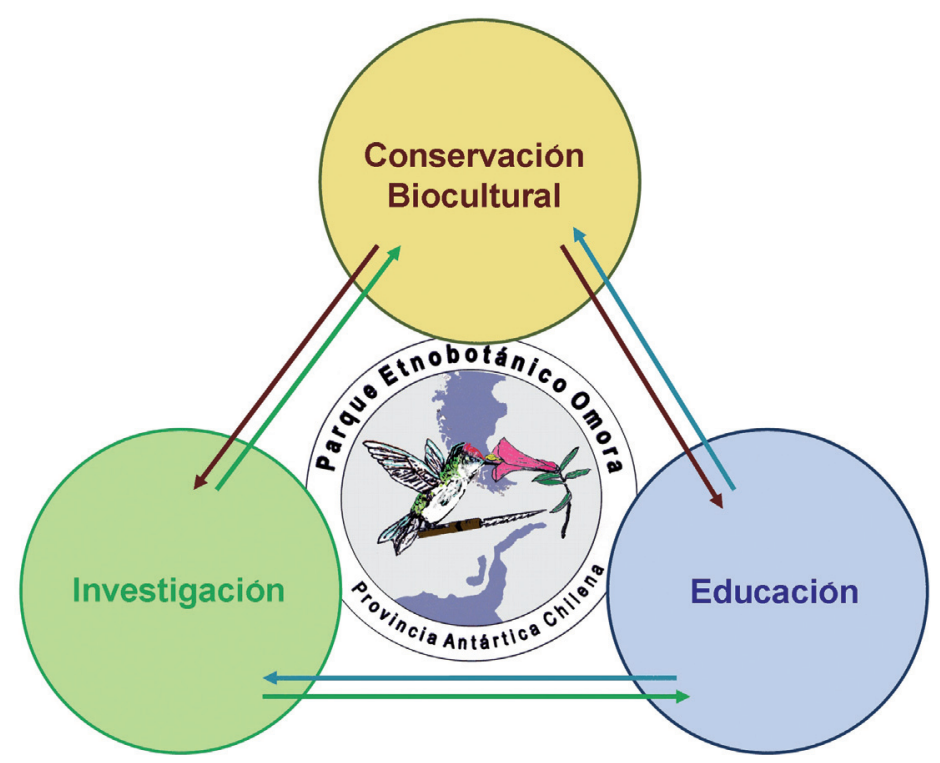

Fig. 4: El programa del Parque Etnobotánico Omora tiene tres dominios de acción: i) investigación transdisciplinaria, ii) educación formal e informal, y iii) conservación biocultural. Estos dominios fueron adaptados a partir de aquellos propuestos por Iniciativa para una Biosfera Sustentable (SBI): investigación, educación y toma de decisiones ambientales (Lubchenco et al. 1991a). Los investigadores del Parque Omora también adaptaron el triángulo de actividades originalmente propuesto por la IBS al incorporar flechas bidireccionales que conectan los tres dominios, con el objeto de enfatizar la necesidad de interacciones multidireccionales. El logo de Omora en el centro enfatiza la integración de la diversidad biológica y cultural al dibujar al picaflor Sephanoides sephaniodes $\mathrm{u}$ omora en lengua yagán, portando un arpón (una herramienta tradicionalmente utilizada por el pueblo yagán para atrapar peces en la región del archipiélago subantártico) y visitando una flor de Philesia magellanica o coicopihue (la fuente primaria de néctar para el picaflor en la ecorregión austral). En las narrativas yaganes, omora era percibido como un ave, al mismo que un pequeño hombre o espíritu que mantenía el orden social y ecológico.

The Omora Ethnobotanical Park's three domains of action are: i) transdisciplinary research, ii) formal and informal education, and iii) biocultural conservation. These domains were adapted from those proposed by the Ecological Society of America's Sustainable Biosphere Initiative: research, education, and environmental decision making (Lubchenco et al. 1991a). OEP researchers further adapted SBI's original triangle of activities by adding bi-directional arrows connecting the three domains in order to emphasize the need for multi-directional interactions. Omora's logo at the center emphasizes the integration between biological and cultural diversity by depicting the hummingbird Sephanoides sephaniodes, or omora in Yahgan, carrying a harpoon used by the Yahgan indigenous people to fish in the subantarctic archipelago region, while visiting a flower of the Magellanic copihue (Philesia magellanica), the primary source of nectar for the hummingbird in the austral ecoregion. In the Yahgan narratives, omora is seen as a bird, and at the same time a small person, a spirit who maintains social and ecological order. 
Sustentable (SBI por su sigla en inglés) con el objeto de definir las prioridades de investigación en las ciencias ecológicas, tanto en términos de sus potenciales para avanzar en el conocimiento científico como para contribuir al bienestar humano (Lubchenco et al. 1991). Respecto a este segundo objetivo, a fines del siglo XX era evidente la necesidad de poseer un sólido conocimiento ecológico para promover un uso más sustentable de los recursos naturales del planeta: "aminorar los rápidos procesos de degradación del medio ambiente y potenciar su capacidad para satisfacer las necesidades de la población mundial” (Mooney \& Levin 1991). En Chile, el documento de la SBI fue traducido, publicado y comentado en la Revista Chilena de Historia Natural (Fuentes \& Castilla 1991, Huntley et al. 1991, Lubchenco et al. 1991b). A pesar que la SBI fue criticada como utópica (Rubenstein 1993), su aproximación motivó al primer autor de este artículo a trabajar en la interface de ecología y sociedad, y tuvo una fuerte influencia en la formulación inicial del marco conceptual para la creación de la estación biológica Senda Darwin en la isla grande de Chiloé $\left(42^{\circ} \mathrm{S}\right)$ en 1994 y del Parque Omora en la isla Navarino $\left(55^{\circ} \mathrm{S}\right)$, en la región archipelágica de Cabo de Hornos en 1999 (ver Rozzi et al. 2000, 2006b).

El multifacético programa del Parque Omora adoptó el triángulo de la SBI que proponía tres áreas esenciales de trabajo: “i) investigación básica para la adquisición de conocimiento ecológico, ii) comunicación de este conocimiento a los ciudadanos, iii) incorporación de dicho conocimiento en la toma de decisiones políticas y manejo de los recursos naturales" (Lubchenco et al. 1991a, p. 373). Respecto a este último, el principal objetivo de la SBI fue "hacer el conocimiento ecológico disponible para los tomadores de decisiones y administradores" (Barber \& Matson 2000). Esta afirmación enfatiza un tipo de comunicación unidireccional del conocimiento ecológico: desde la ciencia hacia la sociedad. Este concepto de difusión unidireccional de la ciencia, en inglés "outreach" (i.e. "reaching out"), es notablemente intrusivo en los programas LTER y en la mayoría de las instituciones científicas. En Chile, por ejemplo, el programa oficial de educación de la ciencia de CONICYT establece explícitamente que las actividades del programa están orientadas a "comunicar los beneficios y avances de la ciencia y tecnología” (http://www.conicyt.cl/573/ article-3463.html). Bajo esta aproximación, la incorporación de la educación ha sido concebida fundamentalmente como una tarea de extensión hacia la sociedad a través de la incorporación de resultados y métodos de la investigación científica en procesos de toma de decisiones y programas educativos.

El programa del Parque Omora ha procurado revertir esta comunicación fundamentalmente unidireccional por medio de un trabajo colaborativo continuo con autoridades, educadores y otros actores relevantes durante procesos políticos de toma de decisiones ambientales y de desarrollo de programas educativos. Más que centrarse en la preparación de informes o en la publicación de información científica que podría llegar a ser usada por tomadores de decisiones o educadores, hemos establecido dinámicas de trabajo multidireccionales. Simbólicamente, para subrayar los procesos dialógicos de toma de decisiones y aprendizajes recíprocos, los investigadores del Parque Omora han modificado el triángulo original de actividades de la SBI incorporando flechas bidireccionales (Fig. 5). Además, sustituimos el tercer dominio de actividades del triángulo de la SBI ("incorporación del conocimiento científico en la toma de decisiones y políticas ambientales") por el de "conservación biocultural". Esta redefinición enfatiza una vez más que para contribuir a procesos sustentables no basta que los científicos generen conocimiento para la toma de decisiones, sino que es esencial que participen en colaboraciones interinstitucionales a largo plazo y con diversos grupos socio-culturales. Aunque sutil, este cambio en el diseño del triángulo ha servido para promover interacciones más recíprocas entre ecólogos y otros actores sociales a través de programas transdisciplinarios de investigación socioecológica a largo plazo (Rozzi et al. 2006a).

En resumen, para alcanzar una biosfera sustentable o para integrar el Hombre y la Biosfera $(\mathrm{MaB})$, nuestras adaptaciones locales de estos programas de la Sociedad de Ecología de EE.UU. y de UNESCO, respectivamente, subrayan la importancia de establecer sitios de 
investigación socioecológica a largo plazo que incluyan investigadores preparados y disponibles para colaborar con diversos actores sociales. No basta con publicar artículos científicos o generar informes de consultorías que son las "metodologías" más recompensadas en la evaluación académica y agencias de financiamiento nacional e internacional. En base a la experiencia del Programa de Conservación Biocultural Subantártica del Parque Etnobotánico Omora, los participantes de las universidades, la comunidad y el Gobierno de Chile hemos identificado (a posteriori) diez principios que han sido efectivos para integrar la investigación socioecológica a largo plazo en la implementación de políticas ambientales sustentables (adaptado de Rozzi et al. 2006a):

1) Experiencia in situ, por parte de los tomadores de decisiones, investigadores y otros participantes en "encuentros directos" (cara a cara) con seres humanos y no humanos en sus hábitats regionales;

2) integración transdisciplinaria de las ciencias, las artes, la filosofía y la toma de decisiones ambientales;

3) identificación e implementación de especies carismáticas tales como el picaflor chico (Sephanoides sephaniodes) u omora en lengua yagán que actúan como símbolos de la riqueza biocultural regional;

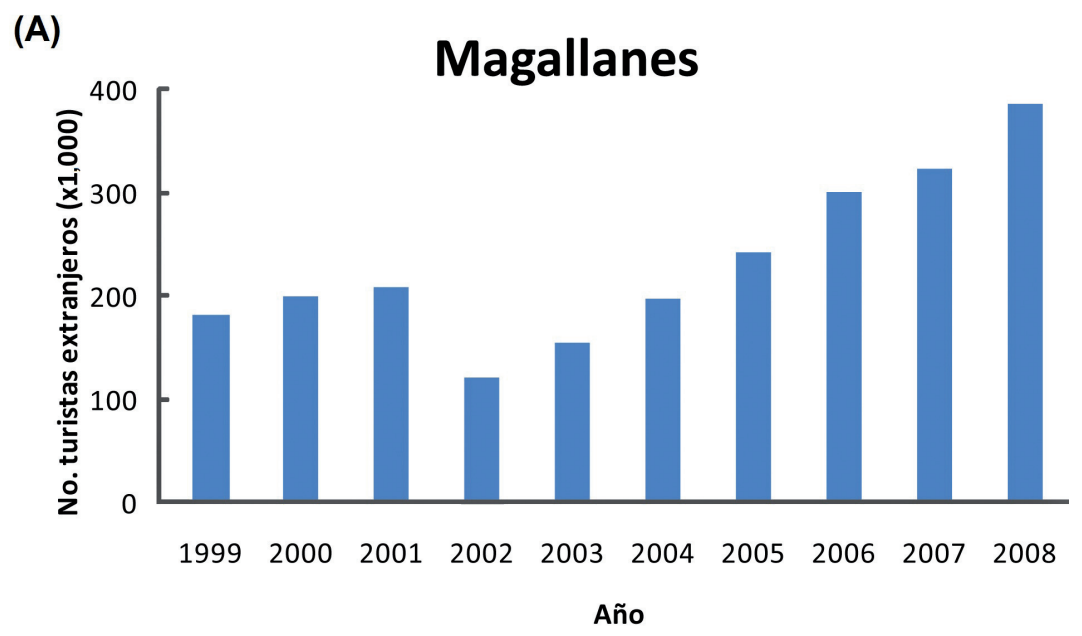

(B)

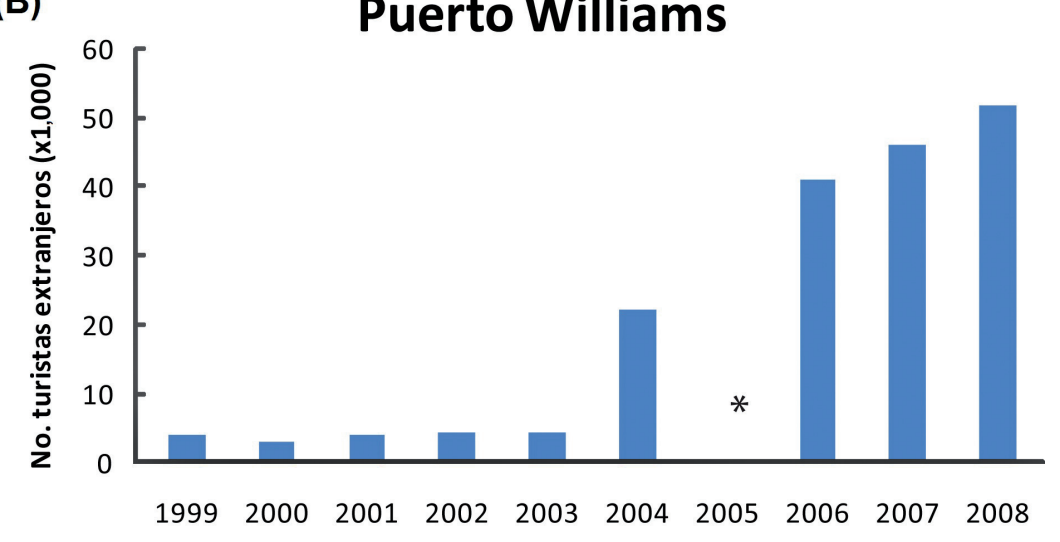

Año

Fig. 5: Número de visitantes extranjeros por año a la Región de Magallanes (A) y a Puerto Williams (B) durante la última década (Fuente: INE-SERNATUR 2008).

Number of foreign visitors per year to the Magallanes Region (A) and Puerto Williams (B) during the last decade (Source: INE-SERNATUR 2008). 
4) continua comunicación de los resultados, conflictos y acciones a través de los medios de prensa y difusión;

5) aproximación participativa, compartiendo procesos de trabajo en educación y conservación, y no solo entregando información;

6) cooperación interinstitucional;

7 creación de redes de colaboración con centros de investigación, educación y/o conservación a nivel local, regional e internacional que permitan identificar causas y proponer soluciones para problemas ambientales a diversas escalas geopolíticas;

8) sustentabilidad económica, a través de estrategias que permitan vincular los ecosistemas y prácticas económicas locales con economías nacionales e internacionales, por ejemplo, a través de programas de turismo de intereses especiales;

9) sustentabilidad administrativa, a través del establecimiento de infraestructura, áreas de conservación y programas de investigación socioecológica a largo plazo; por ejemplo, la Estación de Campo Cabo de Hornos asociada al Parque Omora o la planificación territorial a través de la zonificación de la Reserva de Biosfera Cabo de Hornos, adaptando el modelo del Programa del Hombre y la Biosfera Reservas de Biosfera de UNESCO;

10) sustentabilidad conceptual a través del establecimiento de programas transdisciplinarios de investigación, educación y conservación biocultural in situ a largo plazo, acoplados con las dinámicas políticas, económicas y ambientales locales, nacionales e internacionales.

En otros artículos hemos descrito in extenso estos diez principios que han guiado la contribución del Parque Etnobotánico Omora para la creación de la Reserva de Biosfera Cabo de Hornos, y el establecimiento del programa de educación, investigación y conservación biocultural subantártico, y podrían ofrecer un punto de partida para otros programas de investigación socioecológica a largo plazo (cfr. Rozzi et al. 2006a). En este artículo queremos concluir ofreciendo una metodología específica para integrar la ecología, la ética ambiental y las artes en el componente social de programas de estudios socioecológicos a largo plazo que procuren contribuir a la integración a la conservación biocultural, a la sustentabilidad y la integración de los seres humanos y la biosfera.

\section{EL CICLO DE CUATRO PASOS: UNA METODO- LOGÍA PARA INTEGRAR LA INVESTIGACIÓN, CONSERVACIÓN Y EDUCACIÓN BIOCULTURAL}

La vitalidad del programa del Parque Etnobotánico Omora depende en gran medida de la participación de académicos y estudiantes con interés en desarrollar investigación que abarca ámbitos ecológicos, sociales y políticos involucrados en la toma de decisiones ambientales. Sin embargo, para sustentar esta actividad en el largo plazo e integrar los ámbitos de investigación ecológica y social -especialmente la ética ambiental-en la educación y conservación biocultural, tuvimos que enfrentar el desafío de diseñar nuevas metodologías y mallas curriculares que permitieran a los estudiantes de postgrado lograr esta integración de una manera sistemática y formal. Para ello, analizamos cuáles pasos habían sido críticos para el logro de resultados en la integración de las dimensiones ecológicas y éticas en la educación y conservación biocultural durante nuestros primeros diez años del programa del Parque Omora, e identificamos un ciclo simple de cuatro pasos que incluyen: i) trabajo de investigación interdisciplinaria ecológica y filosófica, ii) composición de metáforas y comunicación a través de relatos simples, iii) diseño de experiencias de campo guiadas con un sentido ecológico y ético, y iv) definición e implementación de áreas de conservación in situ.

Estos cuatro pasos permiten a los estudiantes de postgrado desarrollar investigación teórica e integrarla en actividades innovadoras de educación y/o conservación biocultural. Más adelante ofrecemos una breve síntesis de los conceptos y actividades que se incluyen en este ciclo de cuatro pasos, y complementamos esta síntesis con la ilustración de los pasos metodológicos de dos casos que forman parte de tesis desarrolladas por estudiantes del Programa de Magíster en Ciencias con Mención en Conservación de la UMAG (Figs. 7 y 8).

\section{III.1. Síntesis del ciclo de cuatro pasos}

Los cuatro pasos que han permitido integrar la investigación ecológica y social en los 
programas de educación y conservación del Parque Omora pueden resumirse en los siguientes conceptos y líneas de acción.

Paso 1: Investigación interdisciplinaria ecológica y filosófica

Los SESELP permiten el desarrollo de programas de investigación transdisciplinaria donde participan diversas instituciones, disciplinas y grupos socioculturales con distintos lenguajes, formas de conocimiento y prácticas ecológicas. El programa de investigación biocultural del Parque Omora estudia la biodiversidad subantártica al mismo tiempo que la diversidad de percepciones, nombres, prácticas ecológicas y cosmovisiones sobre esta biodiversidad. Por ejemplo, respecto al picaflor chico (Sephanoides sephaniodes) los investigadores estudian el contenido de azúcares en el néctar de las flores visitadas por este colibrí, a la vez que registran historias asociadas con sus nombres yagán omora, mapudungun pinda, inglés hummingbird o español picaflor (Fig. 6). Con un filtro de resolución biocultural más fino, se investigan también los conocimientos y perspectivas ecológicas y éticas acerca de la naturaleza albergados por distintos grupos socioculturales e instituciones, tales como autoridades de gobierno, profesores de escuela o personal de la Armada de Chile. Análisis comparativos entre los conocimientos de los diversos grupos socioculturales, sus perspectivas y valores ecológicos, y la comparación de estos con modos de comprensión y valoración derivados de las ciencias ecológicas y de la ética ambiental, permiten identificar similitudes y diferencias entre los varios modos de conocer, valorar y convivir con la diversidad biocultural. A su vez, estos análisis comparativos ayudan a reconocer causas más específicas de algunos problemas ambientales junto con oportunidades para resolverlos (ver Apéndice). Con este fin, la investigación también aborda preguntas acerca de cómo integrar la investigación en los ámbitos de la ecología y la filosofía ambiental en conceptos y prácticas de la educación y conservación biocultural tratados en los siguientes pasos del ciclo.
Paso 2: Composición de metáforas y comunicación a través de relatos simples

El programa del Parque Omora incorpora la composición de metáforas como una fase esencial y requiere que los estudiantes de postgrado compongan metáforas con un doble propósito (i) generar figuras comunicativas con el público general, y (ii) integrar los descubrimientos de la investigación ecológica y filosófica a través de un modo de pensamiento analógico que conduce a una síntesis conceptual de hechos, valores y acciones de educación y/o conservación biocultural. En contraste con visiones prevalentes durante la segunda mitad del siglo $\mathrm{XX}$ que sostienen que las metáforas no pueden formar parte del discurso científico, recientemente se ha propuesto que estas constituyen figuras cognitivo-lingüísticas que forman parte de nuestros esquemas conceptuales y generan un agudo carácter esclarecedor de lo abstracto, tanto en los ámbitos del pensamiento cotidiano como científico (Díaz 2006). Bajo esta perspectiva, las metáforas no constituyen una expresión puramente lingüística, sino que representan más bien una estructura cognitiva fundamental de los seres humanos. Por lo tanto, las metáforas no son solo efectivas para comunicarse con el público, sino también para generar síntesis novedosas de conceptos ecológicos y éticos. Esta práctica recupera el sentido originario del concepto griego de poiesis, que integra la dialéctica de invención y descubrimiento en la práctica de investigación de los estudiantes. En apoyo a nuestra perspectiva, durante la última década se ha documentado vastamente el papel central que las metáforas han tenido en el desarrollo del pensamiento científico (Lakoff \& Johnson 1980, Rozzi 1999, 2001, Pickett \& Cadenasso 2002, Díaz 2006).

Cuando iniciamos el programa educativo del Parque Omora, enfatizamos en su marco conceptual la importancia del pensamiento analógico y lúdico (Maturana 1997, Rozzi et al. 1997). Luego, identificamos dos metáforas utilizadas por Charles Darwin en el desarrollo de su teoría evolutiva que sintetizan conceptos centrales tanto de las ciencias evolutivoecológicas como de la ética ambiental: el árbol de la vida y la red de la vida (Rozzi 1999). En la 
primera metáfora, el tronco común del árbol evolutivo ofrece una representación visual de la teoría darwiniana de la evolución que enfatiza el origen biológico común que los humanos compartimos con todos los seres vivos. Esta imagen de una genealogía evolutiva común, estimula un sentido de parentesco que desafía la moralidad occidental tradicional al demandar una extensión del respeto ético más allá de los límites de nuestra propia especie. El sentido de parentesco evolutivo provee uno de los fundamentos científicos que más apelan a la noción del valor intrínseco de la vida no humana. Por otra parte, la metáfora de la red de la vida provee una imagen complementaria que evoca las múltiples interacciones ecológicas que ocurren entre las plantas, algas, animales, hongos, bacterias, nutrientes minerales, aguas, energía solar y suelos que conforman las comunidades bióticas y los ecosistemas. Esta comprensión de las interrelaciones ecológicas provee uno de los fundamentos científicos para la noción del valor instrumental de la biodiversidad, en cuanto provee servicios ecosistémicos para las sociedades humanas.

Las metáforas darwinianas han llegado a ser "mensajeros culturales" que han estimulado la imaginación de científicos, escritores y conservacionistas alrededor del mundo. En el programa del Parque Omora, estas metáforas han ayudado a concebir la integración de nociones ecológicas y éticas a través de la composición de nuevas metáforas

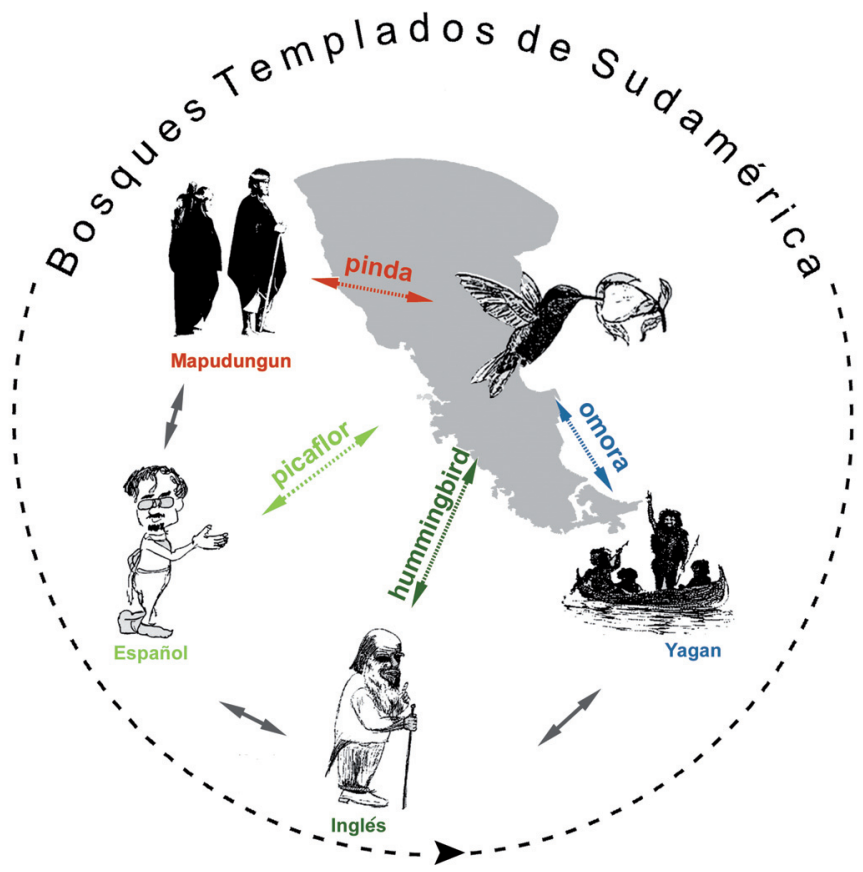

Fig. 6: Cuatro lenguajes hablados en la región de los bosques templados y subantárticos del sur de Chile, que involucran diversas percepciones y cosmovisiones sobre los ecosistemas, su biodiversidad y la forma de habitarlos, y proveen una base para análisis comparativos del conocimiento ecológico amerindio y científico. Por ejemplo, los nombres en mapudungun e inglés pinda y hummingbird, aluden al sonido emitido por las alas en el rápido aleteo de esta pequeña ave. El nombre español "picaflor chico" alude al pequeño tamaño del colibrí (Sephanoides sephaniodes), y el nombre yagán omora alude a su aguerrida conducta territorial (Rozzi et al. 2003a).

Four languages spoken in the temperate and sub-Antarctic forests of southern Chile, which involve diverse perspectives and worldviews about ecosystems, their biodiversity and ways of inhabiting, and provide a basis for comparative analysis of indigenous and scientific ecological knowledge. For example, the names in Mapudungun and English pinda and hummingbird, allude to the sound produced by the rapid movements of the wings during the flight of this little bird. The Spanish name "picaflor chico" points out the small size of the hummingbird (Sephanoides sephaniodes), and the Yahgan name omora refers to its territorial behavior (Modified from Rozzi et al. 2003a). 
y actividades de campo basadas en ellas. La imagen del árbol de la vida ofreció un estímulo inicial para concebir la experiencia de mirarse a los ojos con las aves, en sus hábitats o capturadas en redes de neblina, y constatar la similitud de sus ojos y nuestros ojos humanos (Rozzi et al. 2005). Luego, esta experiencia condujo a una innovadora actividad ecoturística llamada metafóricamente "cara a cara con el caracara” o tiuque (Milvago chimango) (Fig. 8). La imagen de la red de la vida inspiró la creación de otra metáfora: "los bosques en miniatura del Cabo de Hornos”, que ha facilitado la apreciación de la red de interacciones entre musgos, líquenes, insectos y otros pequeños organismos a través de la actividad del ecoturismo con lupa (Fig. 7). La composición de estas metáforas ha surgido a partir de interacciones interdisciplinarias entre los estudiantes de postgrado, ecólogos, filósofos, y otros participantes, como músicos, escultores, periodistas, profesores y escolares en talleres de educación y ecoturismo, o durante cursos de conservación biocultural pre y postgrado.

Paso 3: Actividades de campo guiadas con un sentido ecológico y ético

El programa educativo del Parque Omora enfatiza los "encuentros directos" con diversos seres humanos y con musgos, líquenes, aves, algas, ríos y otros seres que componen los ecosistemas (Rozzi et al. 2002, 2005). Estas experiencias educativas de ecología y filosofía ambiental de campo están diseñadas para estimular la percepción y valoración de la diversidad biológica y cultural en sitios y momentos específicos (Rozzi et al. 2006a). A través de los "encuentros directos" con la diversidad biocultural, recuperamos la conciencia de nuestra coexistencia con la multiplicidad de seres humanos y no humanos con quienes cohabitamos en nuestros hábitats regionales (Rozzi et al. 2008a).

Más del $50 \%$ de la población humana mundial vive hoy en ciudades (Flavin 2007). Por lo tanto, el conocimiento que la mayoría de la gente tiene acerca de la diversidad biológica y cultural es adquirido en contextos urbanos, distanciados física y emocionalmente de hábitats eco-culturales remotos como Cabo de Hornos, donde transcurren las vidas de la mayoría de las especies biológicas y de los lenguajes a comienzos del siglo XXI. La exposición a los hábitats naturales, su belleza y diversidad de habitantes ha llegado a ser una experiencia cada vez más escasa en la educación formal (Feinsinger et al. 1997, Feinsinger 2001, Leopold 2004, Louv 2005, Smith 2004). El conocimiento que las personas adquieren en los centros urbanos acerca de la diversidad biocultural es distanciado aún más de la naturaleza única de otros seres vivos, lenguajes y culturas, debido a que este se enseña a través de los "lentes conceptuales" impuestos por unos pocos lenguajes y modelos matemáticos (Rozzi 2004).

Más del $50 \%$ de la población humana habla hoy uno de los diez lenguajes imperiales dominantes (mandarín, hindú, español, árabe, inglés, ruso, alemán, francés, portugués y bengalí) (Rozzi \& Poole 2007). Menos de 500 lenguajes de las 6,912 lenguas que todavía se hablan en el mundo se enseñan en la educación formal de alguna urbe o escuela rural (Krauss 1992, Maffi 2001). Este filtro deja fuera más del $90 \%$ de los lenguajes y cosmovisiones para comprender y habitar el mundo, y genera un sesgo conceptual en el conocimiento diseminado a través de libros, computadores y otros medios audiovisuales que se basan en unos pocos lenguajes y modelos matemáticos (Rozzi et al. 2006a).

La aproximación educativa del Parque Omora procura remediar esta reducción de la diversidad biocultural. Para ello diseña talleres y cursos de campo que permiten cruzar tanto las barreras físicas de la infraestructura urbana y tecnológica, como las barreras conceptuales de los lenguajes que mediatizan y sesgan la comprensión de la diversidad biológica y cultural. Para los participantes en los talleres, la experiencia de encuentros (o reencuentros) directos "cara a cara" con seres vivos en sus hábitats en Cabo de Hornos, ha sido esencial para lograr una comprensión biocultural. No se trata solo de lecturas sobre aves como el picaflor chico, o de aprender su nombre e historia yagán omora, sino que se generan instantes de coexistencia donde la diversidad biocultural deja de ser únicamente un concepto y comienza a ser una experiencia de cohabitación con diversos seres vivos e historias de vidas, que regularmente permanecen fuera del dominio experiencial de 
la educación formal. Las experiencias de ecología y filosofía ambiental de campo compensan el exceso de información mediatizada que prevalece en la educación formal e informal actual promueven. En cambio, experiencias de "encuentros directos" en los hábitats terrestres y marinos que transforman no solo el conocimiento acerca de la biodiversidad, sino también, la ética del habitar y convivir en los ecosistemas regionales (Rozzi et al. 2005, 2006a).

Paso 4: Implementación de áreas para la conservación biocultural in situ

La habilitación de espacios físicos para la conservación in situ cumple tres funciones esenciales en el Parque Etnobotánico Omora: i) preservación de la diversidad de especies de flora vascular y no vascular, fauna vertebrada e invertebrada y otros grupos de organismos; ii) protección de los hábitats y de las interacciones ecológicas entre las especies que constituyen sus comunidades biológicas; iii) posibilita a los visitantes la experiencia de observar y disfrutar in situ las interacciones ecológicas entre las diversas especies biológicas, y tener por un instante la vivencia de convivir en esta diversidad biocultural. Este último propósito de la conservación in situ en el Parque Omora recupera el sentido ancestral de la ética, arraigado en el término griego ethos (Rozzi et al. 2008).

La palabra ética se origina del término griego ethos, que en su forma más arcaica significa madriguera, la morada de un animal. Por una extensión del uso de esta palabra, su significado llegó a incluir las moradas de los seres humanos, y más tarde este sustantivo también llegó a ser el verbo morar. Esta doble interpretación del término griego ethos como sustantivo y verbo, es expresada luego por dos palabras latinas: hábitat y habitar. A su vez, desde la recurrencia de la acción de habitar un hábitat emergen formas recurrentes de habitar que configuran hábitos o costumbres, que definen el ethos de los habitantes animales y humanos. Las vivencias posibilitadas en espacios de conservación como el Jardín de los Bosques en Miniatura del Cabo de Hornos, (Fig. 7) permiten recuperar a comienzos del siglo XXI una comprensión del concepto de ética que integra tanto el hábitat como también los hábitos que surgen en los modos de cohabitar en los ecosistemas regionales (Rozzi 2009). A través del trabajo de habilitación de estas áreas de conservación in situ, los estudiantes y participantes adquieren un sentido de responsabilidad como ciudadanos ecológicamente educados y éticamente activos en el cuidado de los hábitats, sus formas de vida y servicios ecosistémicos (Rozzi et al. 2008).

\section{III.2. Implementación del ciclo de cuatro pasos en el ecoturismo subantártico}

Los métodos y modelos permiten traducir los conceptos en acciones efectivas. Con el fin de ilustrar los pasos metodológicos involucrados en la integración entre las ciencias ecológica y la filosofía ambiental de campo en la práctica de la conservación y la educación biocultural, describimos dos actividades de ecoturismo subantártico diseñadas e implementadas por el equipo de trabajo del Parque Etnobotánico Omora utilizando el modelo del ciclo de cuatro pasos: 1) ecoturismo con lupa, y 2) ecoturismo "cara a cara" con las aves.

\section{III.2.1. "Ecoturismo con lupa"}

La Fig. 7 ilustra el modelo metodológico del ciclo de cuatro pasos utilizado en la gestación del ecoturismo con lupa. Para cada uno de los pasos se señala el nombre del paso en color azul (primera línea de texto en cada esfera), el método utilizado en color verde (segunda línea en cada esfera), y los logros alcanzados para la conservación en color negro (tercera línea en cada esfera). El desarrollo de los cuatro pasos ha tenido lugar dentro de espacios habilitados en el Parque Etnobotánico Omora que, a su vez, se encuentran embebidos dentro de la Reserva de Biosfera Cabo de Hornos (RBCH). Las líneas $\mathrm{y}$ flechas indican que las interacciones entre los cuatro pasos son multidireccionales. A continuación describimos sucintamente cada uno de los pasos.

Paso 1. Investigación interdisciplinaria: Inventarios de flora no vascular

Desde el año 2000 el equipo interdisciplinario del Parque Etnobotánico Omora ha desarrollado inventarios florísticos en la $\mathrm{RBCH}$. 


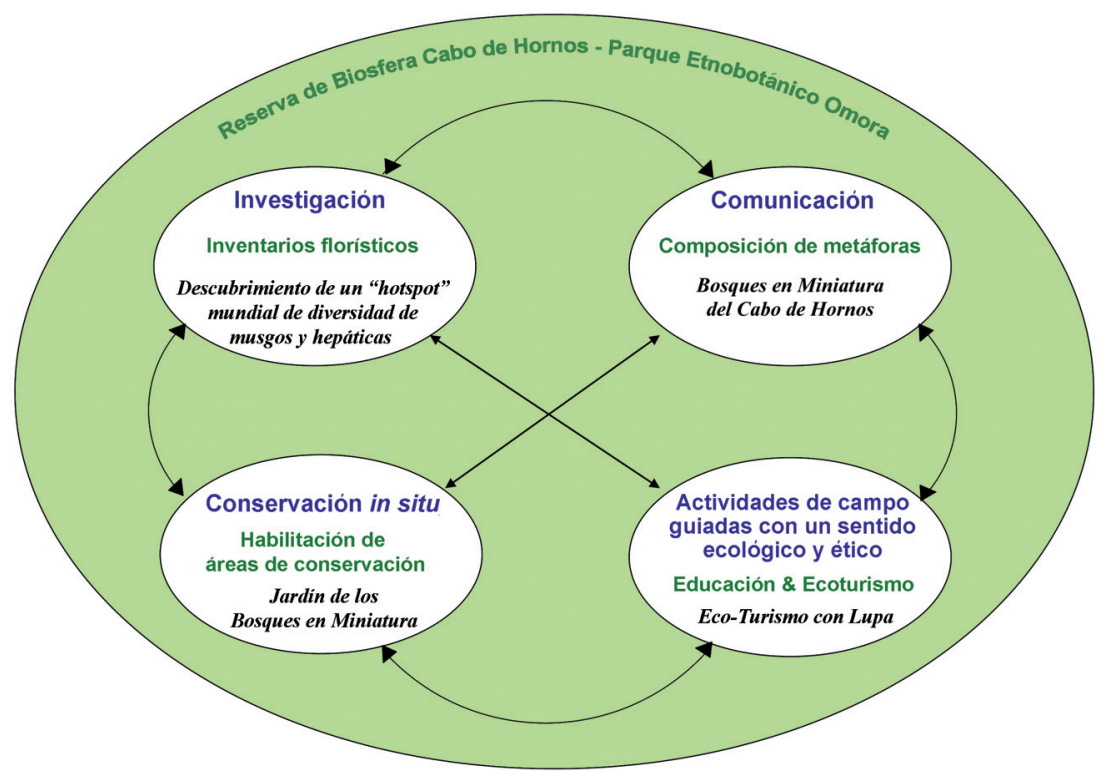

Fig. 7: El ciclo de cuatro pasos para integrar las ciencias ecológicas y la ética ambiental en la conservación biocultural es utilizado por los estudiante de postgrado de la Universidad de Magallanes, quienes desarrollan actividades innovadoras de educación y ecoturismo, tales como el "Ecoturismo con Lupa" en el Parque Omora y la Reserva de Biosfera Cabo de Hornos.

The four step cycle methodology to integrate ecological sciences and environmental ethics into biocultural conservation, which is used by graduate students at the Universidad de Magallanes to develop innovative educational and ecotourism activities, such as "Ecotourism with a Hand Lens".

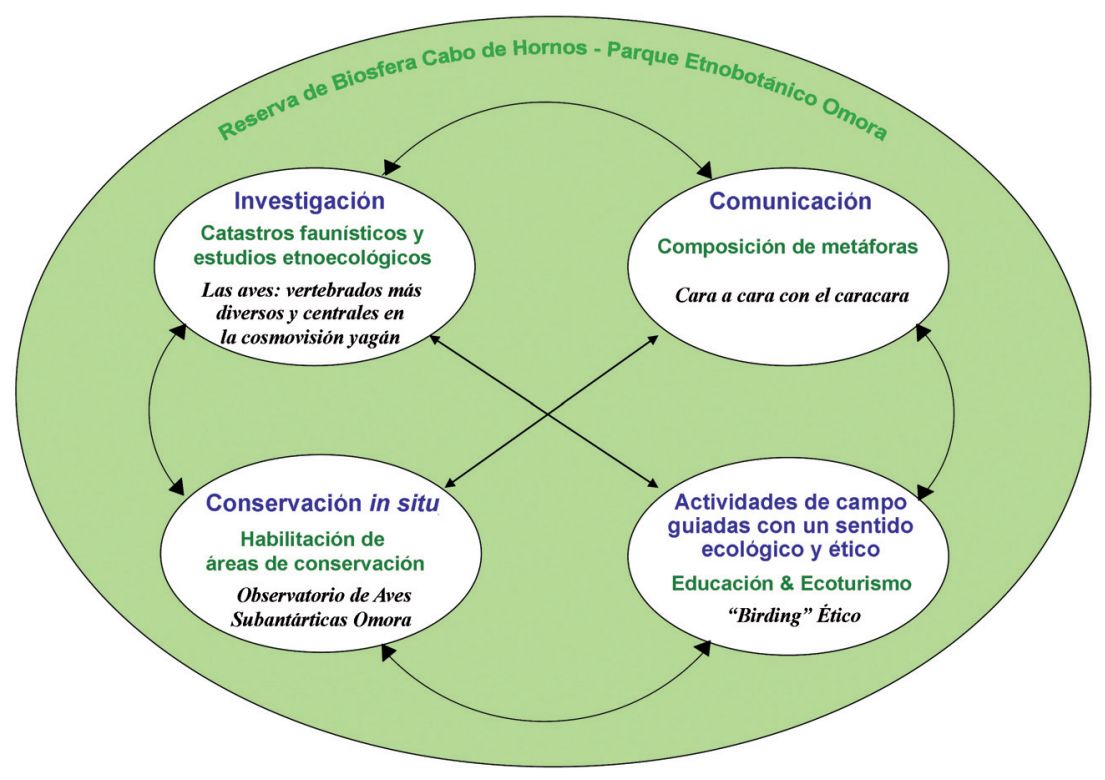

Fig. 8: Ciclo de los cuatro pasos involucrados en el desarrollo de la propuesta del "Birding Ético" en el Parque Etnobotánico Omora en la Reserva de Biosfera Cabo de Hornos.

Methodology of the four step cycle involved in the creation of the "Ethical Birding" activity at Omora Park in the Cape Horn Biosphere Reserve. 
Esta investigación ha llevado a determinar que la flora más diversa está representada por las briófitas, que incluyen al menos 450 especies de musgos y 368 de hepáticas, totalizando 818 especies en la ecorregión subantártica de Magallanes (Rozzi et al. 2008b). Este número supera al de 773 especies de plantas vasculares registradas para esta misma ecorregión. A escala global, este hecho es muy llamativo por al menos dos razones:

i) A nivel planetario, se han descrito hasta el momento unas 300,000 especies de plantas vasculares y sólo unas 15,000 de especies novasculares o briófitas (Goffinet et al. 2006). En la mayoría de las ecorregiones del planeta el número de especies de plantas vasculares es muy superior (aproximadamente 20 veces mayor) al de plantas no vasculares.

ii) La ecorregión subantártica de Magallanes se extiende por unos $125,000 \mathrm{~km}^{2}$, que representan menos de un $0.01 \%$ de la superficie terrestre del planeta. Sin embargo, en esta pequeña superficie archipelágica se encuentra más del $5 \%$ de las especies conocidas de briófitas a nivel mundial. Más aún, se estima que el grado de endemismo de las especies de musgos y hepáticas supera el 50 \% (Engel 1978, Matteri 2000, Villagrán et al. 2005).

Por estas razones se ha identificado a la ecorregión subantártica de Magallanes como un "hotspot" de diversidad de briófitas a nivel mundial (Rozzi et al. 2008b).

Paso 2. Composición de metáforas y comunicación: Bosques en Miniatura del Cabo de Hornos

Los resultados anteriores llamaron la atención no solo de la comunidad científica, sino también de las autoridades, tomadores de decisiones, operadores turísticos y el público general. Sin embargo, para los científicos la transmisión y comunicación de estos descubrimientos acerca de la alta diversidad de briófitas planteó un gran desafío, puesto que a menudo las pequeñas plantas no vasculares carecen de nombres comunes y son desconocidas para la mayoría de los tomadores de decisiones y el público general. Para superar esta dificultad, la invención de una metáfora fue de gran utilidad. Trabajando en conjunto con los jóvenes estudiantes de escuelas primarias, los científicos denominaron "Bosques en Miniatura del Cabo de Hornos" al conjunto de las comunidades bióticas formadas por las diversas especies de musgos, hepáticas, líquenes, hongos y diminutos invertebrados asociados (Rozzi et al. 2002).

Esta metáfora surgió a partir de un pensamiento analógico que compara a las pequeñas comunidades de plantas novasculares con aquellas formadas por grandes árboles, arbustos, lianas y epífitas, habitadas por aves y otros organismos. Esta analogía facilitó significativamente la comprensión y comunicación acerca de las interacciones ecológicas y procesos ecosistémicos que tienen lugar en las pequeñas formaciones de briófitas, líquenes, hongos, bacterias, fauna asociada, suelo y agua. Además, la percepción acerca de los organismos que forman estas comunidades bióticas y ecosistemas adquirió una dimensión ética a través de expresiones como "pueblo de insectos" acuñadas por los escolares.

A través de sus imágenes ecosistémicas y éticas, la metáfora de los bosques en miniatura ha estimulado múltiples actividades educativas que integran las ciencias, las artes y la ética ambiental, tales como la pieza de títeres "La Presumida Señorita Cladonia” y el proyecto EXPLORA-CONICYT "Pequeños Exploradores de los Bosques en Miniatura del Cabo de Hornos" desarrollado en el Parque Omora en el 2009. Este último contribuyó a la creación de una nueva línea de educación a nivel nacional en el Programa de Difusión de la Ciencia y Tecnología EXPLORA-CONICYT: los "Clubes Explorines", que integran por primera vez en Chile la educación de la ciencia a nivel preescolar. De esta manera, el uso de esta metáfora ha apelado a un amplio espectro de grupos etarios y socioculturales, para quienes la existencia de las briófitas era previamente casi completamente desconocida (Medina et al. datos no publicados).

Paso 3. Experiencias de campo guiadas con un sentido ecológico y ético: Ecoturismo con lupa

Los descubrimientos florísticos y las experiencias de exploración de los bosques en miniatura de Cabo de Hornos se han traducido en una innovadora actividad de turismo científico a través de otro nombre metafórico: el ecoturismo con lupa. Lupa en mano, esta actividad invita a los turistas y otros visitantes 
a observar, disfrutar y valorar la belleza, diversidad e importancia ecológica de organismos pequeños como líquenes, musgos, hepáticas, hongos, insectos y otros invertebrados, que usualmente pasan desapercibidos y que no se habían incorporado previamente a las temáticas turísticas de Chile (Rozzi 2005). Los estudiantes de postgrado actúan como guías o educan a guías locales quienes comparten el conocimiento científico en forma didáctica, entretenida e interactiva, a lo largo de senderos interpretativos en el Parque Etnobotánico Omora, acompañando a autoridades, profesores, miembros de la comunidad local, periodistas y grupos de ecoturismo.

El ecoturismo con lupa constituye hoy una nueva actividad de turismo científico en la Región de Magallanes y Antártica Chilena que permite: a) conocer la belleza, diversidad e importancia ecológica de la flora no vascular del extremo austral del Continente Americano; b) invitar a los visitantes a detenerse, bajar su ritmo, y reencontrarse en medio de otros seres; y c) generar nuevas oportunidades de desarrollo turístico ambiental y económicamente sustentable para la comunidad local en la RBCH, como también para la comunidad regional, nacional e internacional. Esta idea innovadora ha encontrado el apoyo del Gobierno de Chile a través del financiamiento de cursos de capacitación y publicaciones acerca de briofitas y líquenes (Goffinet et al. 2006).

Durante la última década, la actividad turística y el número de visitantes han tenido un crecimiento anual de $7.7 \%$, en Chile, una cifra mayor a la tasa de un $4.1 \%$ registrada a nivel mundial (Chacón 2002). En la Región de Magallanes el número de visitantes ha superado el millón el año 2008, una cifra que es un orden de magnitud superior al número de turistas registrados hace dos décadas en la región (INE-SERNATUR 1999-2008). En este escenario, el ecoturismo con lupa representa una diversificación y fortalecimiento de la oferta turística, que en una administración coordinada con las autoridades y servicios públicos ofrece una fuente de ingresos ambiental y económicamente sustentable para la comunidad local que habita en la $\mathrm{RBCH}$, y podría hacerlo para otras regiones del país y del mundo. El carácter sustentable de esta actividad radica fundamentalmente en seis atributos del ecoturismo con lupa.

i) Es anual, debido a que puede practicarse durante todo el año. En contraste con otras actividades de turismo de naturaleza, tales como "bird-watching" o "whaling", que presentan una marcada estacionalidad, el ecoturismo con lupa extendie la temporada turística al invierno, verano, primavera y otoño.

ii) Tiene un bajo impacto ambiental, debido a que requiere un área geográfica pequeña; en un reducido espacio el turista puede observar una gran diversidad de especies.

iii) Prolonga el tiempo de estadía del turista en el área, debido a que requiere una actitud pausada y un largo tiempo de observación para descubrir y apreciar la flora de cada roca, tronco y otros sustratos.

iv) Es propio de la región subantártica, puesto que se basa en una singularidad florística derivada de su carácter subpolar. Más aún, la Región de Magallanes y Antártica Chilena podría liderar innovaciones en el turismo sustentable en otras latitudes altas del planeta, puesto que la práctica del ecoturismo con lupa y su atención sobre los "bosques en miniatura" es transferible a otras regiones subpolares o polares del mundo que también presentan una flora dominada por musgos, hepáticas y líquenes.

v) Posee un alto valor educativo, estético y ético porque descubre, disfruta y aprecia el valor de organismos desapercibidos para el común de la gente, y asombran con su belleza $\mathrm{y}$ formas de vida al ser descubiertos.

vi) Contribuye a la identidad regional porque pone de manifiesto la flora más diversa e idiosincrática de la Región de Magallanes y Antártica Chilena.

Paso 4. Implementación de áreas de conservación biocultural in situ: Jardín de los Bosques en Miniatura del Cabo de Hornos

El descubrimiento de la alta diversidad de la brioflora austral y el desarrollo de la actividad de Turismo con Lupa estimuló a un grupo interdisciplinario coordinado por ecólogos, filósofos y artistas para diseñar e iniciar la construcción de un "Jardín de los Bosques en Miniatura del Cabo de Hornos” en el Parque 
Etnobotánico Omora. Con una red de senderos de aproximadamente $2 \mathrm{~km}$ de extensión y 20 estaciones interpretativas implementadas con esculturas, lupas y señaléticas interpretativas, este jardín protege in situ no solo a las poblaciones de diversas especies de musgos, hepáticas y líquenes, sino que también a sus interacciones ecológicas con insectos, hongos, bacterias, aguas, suelos, incluyendo prácticas humanas de uso del suelo, que pueden ser observadas por los visitantes en sus hábitats nativos. El Jardín de los Bosques en Miniatura del Cabo de Hornos es el primer jardín botánico que se dedica a la brioflora con criterios de conservación biocultural, educación, ecoturismo y ética ambiental de campo (Rozzi et al. 2005).

Desde la perspectiva de los turistas y otros visitantes, el Jardín de los Bosques en Miniatura del Cabo de Hornos no solo permite observar mundos diferentes, sino que la actividad del "ecoturismo con lupa" conlleva también una vivencia que se desvía del hábito globalizado de "lo rápido y fácil". Este tipo de turismo requiere un cambio de ritmo, disponerse con concentración y tiempo para que emerjan ante la mirada del visitante las texturas foliares, las tonalidades de los pigmentos o los movimientos de los pequeños invertebrados en medio de esta trama microboscosa. El descubrimiento de los bosques en miniatura conlleva una necesaria disposición de calma y atención para percibir expresiones de vida que quedan ignoradas si se pasa caminando rápido, "queriendo verlo todo y no viendo nada”. Esta vivencia revitaliza al visitante, quien además descubre que en los "Bosques en Miniatura del Cabo de Hornos" lo pequeño es hermoso. Estos acontecimientos provocan y maravillan a los turistas procedentes de un mundo global dominado por lo rápido y cuantitativo, donde "más es mejor" y se tiende a elogiar lo grande. En el acto de indagar la microbiodiversidad, la calma para observar con lupa lo pequeño conlleva también una atención para observarnos a nosotros mismos, con nuestra respiración, emociones y asombro. Se alcanza así una experiencia ecoturística, ética y recreativa de educación informal desplegada en las tramas de diversidad biológica y cultural (Rozzi 2005).

E1 descubrimiento y la observación de estos seres "invisibles" va alimentando nuestra conciencia acerca de cuán poco conocemos de nuestro entorno. Las observaciones de las constantes variaciones e interrelaciones, y las experiencias estéticas y de asombro que surgen al detenernos y observar con una lupa (o el lente de acercamiento de una cámara fotográfica) van invitándonos a revisar las limitaciones de los modos prevalecientes del conocer con un marcado sesgo hacia la enseñanza basada en un único alfabeto y sistema numérico (Rozzi et al. 2005, 2006b). La conciencia acerca de nuestra ignorancia respecto a la diversidad de seres con que cohabitamos debiera invitarnos a actuar con más cautela. En este contexto, el ecoturismo con lupa representa una práctica ética que contribuye a una convivencia respetuosa, a una cohabitación en la diversidad biocultural en que estamos inmersos.

III.2.2. Ecoturismo "cara a cara" con las aves en sus hábitats

Una segunda nueva actividad de ecoturismo subantártico generada por el programa de filosofía ambiental de campo y conservación biocultural del Parque Omora integra la investigación ornitológica y el análisis de sus implicancias para la ética ambiental. Para ilustrarla utilizamos la Fig. 8 que -de manera análoga a la Fig. 7- señala los nombres, métodos y logros alcanzados para la conservación en cada uno de los cuatro pasos del ciclo definido por el programa de investigación, educación y conservación biocultural del Parque Etnobotánico Omora.

Paso 1. Investigación interdisciplinaria: Censos de aves en la Reserva de Biosfera Cabo de Hornos

Los catastros de fauna terrestre realizados en la región archipelágica de la Reserva de Biosfera Cabo de Hornos han determinado que las aves son los vertebrados más abundantes, diversos y conspicuos (Venegas \& Sielfield 1999, Rozzi et al. 2006b). Reptiles y anfibios están completamente ausentes en esta región, y los mamíferos terrestres nativos solo incluyen 9 especies, pertenecientes a 8 géneros, 5 familias y 4 órdenes: 3 especies del orden Rodentia pertenecientes a la familia Cricetidae (Euneomys chinchilloides, 
Oligoryzomys longicaudatus, Abrothrix xanthorhinus), tres especies del orden Carnivora con dos mustélidos (Lontra felina y L. provocax) y un cánido (Lycalopex culpaeus), dos Chiroptera de la familia Vepertilionidae (Histiotus montanus y Myiotis chiloensis), y el guanaco (Lama guanicoe), un camélido como único representante del orden Artiodactyla (Rozzi et al. 2006b). En contraste, las aves incluyen al menos 100 especies, pertenecientes a 76 géneros, 34 familias y 17 órdenes (Rozzi et al. 2006b, JC Pizarro, datos no publicados). En consecuencia, las aves presentan en esta región una riqueza de especies un orden de magnitud mayor que todos los demás vertebrados terrestres.

Las aves ocupan además todo el espectro de hábitats terrestres (altoandinos, complejo de tundra, matorrales y bosques), dulceacuícolas y costeros (Anderson \& Rozzi 2000, Ibarra 2007, Ippi et al. 2009). Los censos de aves realizados en la isla Navarino, a 10 largo de transectos y puntos de conteo, han determinado que el tiuque (Milvago chimango) es la especie más generalista respecto al uso de hábitats (JC Pizarro, datos no publicados). El tiuque es también una especie residente que abunda en los hábitats de bosque, matorral e intermareal durante todos los meses del año. En el intermareal se le observa muy frecuentemente alimentándose de carroña e invertebrados. En el bosque, el tiuque pernocta, nidifica y utiliza las ramas altas como percha. Bajo estos sitios, hemos colectado en el suelo del bosque exoesqueletos de crustáceos y equinodermos (Pseudochinus magellanicus), y conchas pertenecientes al menos a ochos especies de moluscos: choritos (Perimytilus purpuratus, Mytilus chilensis), cholgas (Aulacomya ater), lapas (Fisurella spp.), mauchos (Nacella deurata y $N$. magellanica), chitones (Plaxiphora eurata y poliplacóforos no identificados) (JC Pizarro, datos no publicados). Estas conchas y exoesqueletos transportados por el tiuque poseen altos contenidos de $\mathrm{Ca}$ y $\mathrm{N}$, como también trazas de $\mathrm{Mg}, \mathrm{Si}, \mathrm{Zn}, \mathrm{P}, \mathrm{Mg}$ y otros elementos que podrían representar un aporte significativo de nutrientes, a la vez que modificar el $\mathrm{pH}$ en micrositios en los ecosistemas forestales subantárticos. De esta manera, el tiuque podría generar un "vínculo transecosistémico" relevante entre los ecosistemas costero-marinos y terrestres en la ecorregión subantártica de Magallanes donde los suelos son delgados, recientes y probablemente pobres en nutrientes (JC Pizarro, datos no publicados).

Complementariamente, hemos realizado una investigación en el área de la ética fenomenológica, especialmente la escuela de Emmanuel Lévinas (1969), y en filosofía ambiental con énfasis en las cosmovisiones amerindias yagán y mapuche acerca de las aves (Rozzi et al. 2001, 2003a, Aillapan \& Rozzi 2004, Massardo \& Rozzi 2004, Rozzi 2004). Esta investigación incluye la comparación de estas cosmovisiones ancestrales con nuevas perspectivas científicas acerca de las aves, y con nociones derivadas de la joven subdisciplina de la ética ambiental (Leopold 1949, White 1967, Hardin 1968, Naess 1973). La investigaciones ecológicas y filosóficas de este estudio de la avifauna de Cabo de Hornos se han integrado en conceptos y actividades de educación y conservación biocultural conducidas en el Parque Omora y la RBCH (JC Pizarro, datos no publicados).

Paso 2. Composición de metáforas y comunicación: Cara a cara con el caracara

Con los propósitos de vincular nociones ecológicas y éticas, y de comunicar a un público amplio los descubrimientos derivados de la investigación sobre los ensambles de aves de Cabo de Hornos en general, y sobre la autoecología del tiuque en particular, hemos compuesto la metáfora: cara a cara con el caracara.

Chimango caracara es el nombre común en inglés para el tiuque (Milvago chimango). Caracara es un nombre onomatopéyico de origen Tupi-guaraní que se ha incorporado al inglés para referirse al grupo de falcónidos americanos de patas largas, hábitos carroñeros y generalistas en su dieta (JC Pizarro, datos no publicados). Chimango es el nombre común que se da al tiuque en Argentina, y por parte de los antiguos habitantes en la $\mathrm{RBCH}$. Por ejemplo, Úrsula Calderón y otros antiguos miembros de la comunidad yagán se referían a esta ave como yoskalía en su lengua yagán, y chimango en español. En el resto del territorio chileno, como también para la mayoría de los nuevos pobladores de la $\mathrm{RBCH}$, el nombre 
común más frecuentemente utilizado es el de tiuque, un nombre onomatopéyico derivado del mapudungun triuki que alude a sus vocalizaciones características (Rozzi et al. 2003a).

"Cara a cara" es una expresión utilizada por el filósofo judío-lituano Emmanuel Lévinas. Este "cara a cara" ocurre cuando nos encontramos de frente, directamente con otra persona. En estos encuentros las emociones, como por ejemplo el sufrimiento, de otra persona se nos trasmiten a través de su "rostro" o "cara". Este "cara a cara" evoca en consecuencia una responsabilidad inmediata por la otra persona, anterior a cualquier acción o decisión posterior. Así, Lévinas propone definir la ética humana desde la responsabilidad por "el otro" y una filosofía que comienza en la ética del otro; no en la ontología de un yo soy (ego cartesiano). Lévinas acuñó esta expresión que define una relación ética entre dos seres humanos mientras estuvo cautivo en un campo de concentración en Stammlanger, durante la Segunda Guerra Mundial en 1940 (Dussell 1999).

A pesar que la expresión "cara a cara" de Lévinas permanece dentro del ámbito de ética humana (Davy 2007), su fuerza ética podría extenderse hacia los encuentros con seres no humanos (Rozzi et al. 2008a). Esta extensión coincide con la intencionalidad del concepto de "encuentros directos" acuñado por el Programa de Filosofía Ambiental de Campo del Parque Etnobotánico Omora (Rozzi et al. 2005, 2006a). Los “encuentros directos" se refieren a las experiencias de encuentros con otros seres humanos y no humanos en sus hábitats nativos. En esa experiencia de encuentro, estos seres pueden desplegar sus hábitos y expresar, por tanto, plenamente sus identidades, conformadas como resultado de las historias de interacciones evolutivas recurrentes con otros cohabitantes que componen los ecosistemas (Rozzi 2009). Esta experiencia de "encuentros directos" permite trascender a la comprensión de la biodiversidad que frecuentemente queda reducida al ámbito de nombres e indicadores numéricos cuando las personas no han tenido experiencias en terreno (Rozzi et al. 2008c). En suma, la metáfora cara a cara con el caracara invita a una experiencia de "encuentros directos" entre los observadores de aves (o "birders") y las aves cuya emoción y vitalidad recupera la comprensión del tiuque (las aves y otros organismos) como sujetos y seres vivos integrales.

Paso 3. Experiencias de campo guiadas con un sentido ecológico y ético: Birding ético

Birding es el nombre en inglés de la actividad de observación recreativa de las aves e involucra un estilo de vida que surge de una convivencia sustentable con ellas (cfr. ABA 2006, JC Pizarro, datos no publicados). En el Parque Etnobotánico Omora hemos abordado la observación recreativa de aves por medio de una actividad guiada que se basa en: i) los hallazgos ecológicos acerca del papel ecológico del tiuque y otras aves en interacciones tróficas, dispersión de semillas, transporte de nutrientes entre ecosistemas marinos y terrestres y otros procesos ecosistémicos; y ii) tener la experiencia ética de los encuentros "cara a cara" con las aves y otros organismos. Para ello hemos diseñado visitas guiadas con preescolares, escolares, universitarios, profesores y visitantes en general en las zonas litoral, boscosas, altoandinas y de humedal donde se realizan observaciones de aves, sus anatomías, conductas e interacciones ecológicas.

Ponemos especial atención sobre la observación del tiuque alimentándose de moluscos y otros invertebrados en el intermareal, y cómo vuela con sus capturas en las patas hacia el bosque donde se posa, se alimenta y deja caer al suelo del bosque restos de las conchas o de los exosqueletos. Luego identificamos estos restos y discutimos la importancia potencial de las aves como transportadoras de estos invertebrados desde la costa para la fertilidad del suelo de los bosques. Así, los estudiantes y turistas comparten microexperiencias de indagación científica, más que recibir pasivamente información acerca de la avifauna y los ecosistemas. A partir de estas observaciones, indagaciones y reflexiones, los participantes pueden llegar a concluir que el tiuque y otras aves conectan el mar y la tierra en el archipiélago y de esta forma podrían prestar un "servicio ecosistémico" relevante para la población humana, como este papel en la fertilidad de los suelos a través del transporte 
de nutrientes. En la etapa de reflexión procuramos situar las observaciones y conclusiones obtenidas in situ en contextos ecológicos y escalas geográficas más amplias. Por ejemplo, invitamos a los participantes a pensar en las grandes acumulaciones de guano de colonias reproductivas de aves como las pingüineras en Cabo de Hornos, o de gaviotas y otras aves en el litoral del norte de Chile y Norteamérica que tienen un impacto más conocido y documentado sobre la vegetación natural y el servicio como fertilizantes (Pisano 1980, Ellis et al. 2006). Por un lado, este tipo de conclusiones despiertan en los estudiantes la curiosidad científica de investigar en mayor profundidad el papel ecológico de las aves como vínculo "transecosistémico marino-terrestre". Por otro lado, la comprensión de estos "servicios ecosistémicos" provistos por las aves permite una valoración de su función ecológica informada por la ciencia, que en términos de una ética ambiental conlleva una comprensión del valor instrumental de las aves para la sociedad humana y la integridad de los ecosistemas.

Complementariamente a la indagación ecológica anterior, durante las observaciones de aves hacemos un énfasis en el examen de sus características morfológicas, especialmente el rostro y los ojos. Los participantes realizan una descripción detallada de la morfología mediante dibujos, relatos y otros modos de expresión. A partir de estas descripciones y observaciones formulamos preguntas acerca de similitudes y diferencias que detectan entre, por ejemplo, los ojos humanos y los ojos de las aves. Estas preguntas conducen a reflexiones acerca de nuestro parentesco y modos de convivencia con las aves fundadas en una experiencia de campo en los encuentros "cara a cara", tanto en hábitats marinos como terrestres, que los seres humanos compartimos hoy con las aves y otros seres vivos. En términos de ética ambiental, esta experiencia facilita a los participantes internalizar una comprensión del valor intrínseco de las vidas de las aves. A través de estos encuentros "cara a cara" (face to face) los participantes conciben la posibilidad que las vidas de las aves adquieran un valor en sí mismas, independientemente de su utilidad para el ser humano. Es decir, se supera una visión ética dualista entre seres humanos y no humanos, y las consideraciones éticas pueden extenderse a todas las formas de vida más allá del ámbito del interés humano, incluyendo a las aves y el conjunto de animales con que cohabitamos (Rozzi 2004).

Paso 4. Implementación de áreas de conservación biocultural in situ: Observatorio Omora de aves subantárticas

Para observar y disfrutar la belleza de la diversidad y abundancia de las aves subantárticas, así como para apreciar sus funciones ecológicas, es necesario conservar los hábitats donde se expresan y reproducen plenamente los hábitos de estos habitantes alados. Al mismo tiempo, es primordial habilitar espacios físicos en estos hábitats para practicar actividades educativas ecológicamente guiadas, como el birding ético, y así facilitar un encuentro "cara a cara" con las aves y otros seres vivos que cohabitan con ellas. Por ejemplo, para observar al tiuque en su papel ecológico transecosistémico, es necesario conservar tanto los hábitats del intermareal como los de bosques (Pizarro et al., datos no publicados).

Además de proteger hábitats y habilitar espacios físicos, es necesario consolidar espacios organizacionales para que personas de diversa índole, como investigadores, estudiantes, tesistas y miembros de la comunidad local, interesados en investigar, conocer y disfrutar de la diversidad biocultural de la avifauna, se puedan reunir e interactuar a través de distintas iniciativas.

La diversa configuración de condiciones físicas, hábitats y habitantes de la bahía Róbalo en la costa del Parque Omora, provee refugio y sitios de reproducción, crianza y alimentación a 29 especies de aves marinas, costeras y terrestres en la época estival (Pizarro et al., datos no publicados). Aquí hemos definido un sendero interpretativo que permite: i) minimizar el impacto de los visitantes sobre las aves; ii) definir estaciones para resaltar la belleza y diversidad de los "habitantes, hábitos y habitantes" de la bahía y bosques costeros; iii) suministrar narrativas que enriquezcan la comunicación de los conocimientos y descubrimientos científicos y nociones éticas asociadas a cada una de las estaciones del sendero interpretativo. 


\section{COMENTARIOS FINALES}

En el marco de los rápidos cambios ambientales, sociales y económicos globales, uno de los mayores desafíos para la ecología a inicios del siglo XXI es lograr que la investigación ecológica -que todavía permanece enfocada en escalas locales- pueda abordar escalas globales que permitan también aumentar el número y diversidad de participantes en las todas las fases de la investigación y la toma de decisiones (Herrick \& Saruhkán 2007, Adger et al. 2009). Este desafío puede asumirse de una manera más robusta si es abordado a través de redes de sitios, como lo hacen la Red Chilena de Sitios de Estudios Socio-Ecológicos a Largo Plazo (SESELP) o la Red Internacional de Sitios de Estudios Ecológicos a Largo Plazo. En estas redes los sitios mantienen los programas de investigación socioecológica a escala local, a la vez que abordan preguntas y generan programas a escala global a través del trabajo colaborativo en red. El sistema jerárquico de niveles de organización en estas redes SESELP permite acceder a escalas globales sin sacrificar el mosaico socioecológicamente heterogéneo que solo se capta a través de la investigación socioecológica a escala local. Estas escalas locales adquieren una relevancia creciente para evitar procesos mundiales de homogeneización biótica y cultural derivados de la dominancia de enfoques globales insensibles a las singularidades bioculturales regionales (Rozzi et al. 2008a). Para responder a este doble desafío de articular escalas globales y locales, las redes de sitios de estudios socioecológicos a largo plazo proveen una plataforma ideal puesto que permiten desarrollar programas de investigación que exploran fenómenos y participan en procesos ecosociales que ocurren en múltiples escalas interdepedientes.

Aquí presentamos el programa del Parque Etnobotánico Omora que ha definido tres escalas de trabajo, que le permiten funcionar a escala local como un centro científico de la Reserva de Biosfera Cabo de Hornos, a nivel nacional como un sitio de la primera red chilena de investigación a largo coordinada por el Instituto de Ecología y Biodiversidad (IEB) $\mathrm{y}$ a nivel internacional como una reserva y estación de campo del Programa de
Investigación y Conservación Biocultural Subantártica, coordinado por la UMAG, el IEB y la UNT. Esta organización en unidades anidadas ha permitido articular el trabajo a escalas locales, nacionales e internacionales de manera sinérgica (Fig. 2). Estos programas han permitido descubrir singularidades de la diversidad biológica y cultural de la remota ecorregión subantártica de Magallanes, incorporar la filosofía ambiental en la investigación socioecológica e integrar esta investigación en acciones que favorecen la sustentabilidad económica y ambiental, a la vez que la conservación y respeto por la diversidad biológica y cultural.

Este fortalecimiento e innovación interdisciplinaria nos ha permitido abordar un segundo desafío central de la investigación ecológica a comienzos del siglo XXI: ampliar el espectro de las dimensiones sociales complementando variables económicas con aproximaciones éticas (Likens 1991, Gardiner 2004, Leopold 2004). Una de las mayores dificultades para la integración de la ética en los programas SESELP deriva de una drástica disminución de su enseñanza en los programas de ciencias en EE.UU. y otras regiones del planeta (Likens 1991, Leopold 2004). Esta merma en la enseñanza de la ética ha conllevado un olvido del vocabulario y métodos de deliberación ética (cfr. MacIntyre 1984), un exacerbado énfasis en análisis de costo-beneficio que reducen la ética a una estrecha perspectiva utilirarista (Groome 2008) y una mayor disociación entre la ética ambiental y las ciencias ecológicas (Golley 1993). Por lo tanto, es urgente superar la insuficiencia de metodologías que permitan interrelacionar sistemática y efectivamente investigaciones filosóficas y científicas, valores éticos y hechos ecológicos.

En este artículo hemos expuesto una metodología de filosofía ambiental de campo y conservación biocultural que contribuye a resolver el desafío anterior, integrando dimensiones ecológicas y éticas a través de un ciclo de cuatro pasos en la formación de nuevos profesionales en programas de postgrado, pero también aplicable en múltiples programas de investigación, educación escolar, capacitación y conservación en sitios de estudios socioecológicos a largo plazo. Concisamente, este ciclo considera la siguiente secuencia de 
pasos. Paso 1, investigación ecológica y filosófica interdisciplinaria acerca de la diversidad biológica y cultural, y sobre la diversidad de modos de percibir y cohabitar con esa diversidad biocultural por parte de diferentes grupos socioculturales e instituciones, que viven y trabajan a escalas locales, nacionales e internacionales. Paso 2, composición de metáforas que conducen a una síntesis conceptual de los resultados y comprensión ecológica y ética lograda a través de la investigación transdisciplinaria en el "Paso 1". Estas metáforas deben ser también atractivas para comunicar esta síntesis ecológica y ética a audiencias académicas y no académicas. Paso 3 , actividades de terreno guiadas por las metáforas generadas en el "Paso 2" que procuran liberar de sesgos en la percepción y valoración de la diversidad biocultural asociados con la presencia de barreras físicas (e.g., infraestructura urbana y tecnológica) y conceptuales (e.g., dominancia de unos pocos lenguajes coloniales y modelos matemáticos) en la educación y la vida cotidiana de la mayoría de la gente e instituciones del mundo a comienzos del siglo XXI. A través de "encuentros directos" la metodología de filosofía ambiental de campo contribuye a recuperar una conciencia y comprensión de nuestra coexistencia con diversos seres humanos $\mathrm{y}$ no humanos en hábitats bioculturalmente heterogéneos. Paso 4, generación de áreas de conservación in situ que permiten la continuidad de diversas interacciones bioculturales en hábitats locales, y posibilitan al participante asumir una acción responsable, ecológica y éticamente informada.

La secuencia de cuatro pasos ensaya interrelaciones entre las investigaciones y actividades ecológicas y éticas que diversifican aproximaciones prevalentes de éticas utilitaristas, basadas en cálculos de costobeneficio (Broome 2008). Además, la investigación sociocultural y la construcción participativa de conceptos y actividades educativas y de ecoturismo para la conservación posibilitan una aproximación multicultural a la ética ambiental, arraigada en contextos ecológicos culturales específicos. Esta metodología de filosofía ambiental de campo promueve experiencias transformativas en los estudiantes, investigadores y demás participantes, quienes transitan desde la investigación ecológica-filosófica hacia acciones éticamente responsables que estimulan, a su vez, nuevas preguntas de investigación, metáforas y actividades de campo. Se genera así una espiral dinámica de integraciones ecológicas y éticas, de manera dialéctica e inmersas en una conciencia de co-habitar que recupera un sentido ecológico de la ética, que tiene también raíces en el significado presocrático del término ethos, que luego originó la palabra ética (Rozzi et al. 2008a).

La efectividad de la metodología del ciclo de cuatro pasos para la integración de la ecología y la ética ambiental en programas de educación está siendo evaluada actualmente a través del proyecto "Integrando las ciencias ecológicas y la ética ambiental para la conservación biocultural de la región subantártica del suroeste de Sudamérica”. Este proyecto de tres años es financiado por el programa Experiencias de Investigación Internacional para Estudiantes (IRES, por su sigla del inglés International Research Experiences for Students) de la Fundación Nacional de la Ciencia (NSF, National Science Foundation) de EE.UU., y a través de contrapartes chilenas del IEB permite que estudiantes de postgrado y pregrado de Chile y Estados Unidos trabajen en conjunto con investigadores del Parque Omora y la Red SESELP. El objetivo de valorar la diversidad biológica y cultural es compartido con la Estrategia para la Educación Ecológica, Diversidad y Sustentabilidad (SEEDS, Strategies for Ecology Education, Diversity and Sustainability: Diverse People for a Diverse Science) de la Sociedad de Ecología de EE.UU. (por sus siglas en inglés, ESA SEEDS), y el proyecto NSF-IRES ha permitido además que SEEDS participe en esta evaluación de la efectividad del ciclo de cuatro pasos y la aproximación de la filosofía ambiental de campo.

Nuestro proyecto NSF-IRES ha permitido, por otra parte, que el programa SEEDS haya incorporado por primera vez un componente internacional en su iniciativa. Esta sinergia entre ambos programas procura promover perspectivas multiculturales y contribuir a la conservación biocultural tanto a escala local como global. Este año 2010, en la Reunión Anual de la Sociedad de Ecología de EE.UU. se sostendrá además una reunión cumbre en 
educación llamada “¿Cómo se verá la Educación Ecológica en el 2020?”, que ha definido como uno de sus tres objetivos centrales subrayar algunos de los avances en experiencias transformativas en la educación ecológica en redes de investigación a largo plazo y en el diseño de nuevas mallas curriculares (Lowman \& Randle 2009).

Con raíces como una iniciativa local, el programa del Parque Etnobotánico Omora ha abarcado luego escalas nacionales e internacionales para poder enfrentar de manera efectiva desafíos globales, a través de una alianza de instituciones académicas ubicadas principalmente en Chile y en Estados Unidos y con la colaboración de una red de investigadores de diversas partes del mundo. Por sus resultados en la integración de la academia y la sociedad, el programa del Parque Omora fue reconocido por sus esfuerzos con el Premio Ciencia y Práctica de la Ecología y Sociedad, en el año 2008 (Hargrove et al. 2008). Este premio expresa cómo la habilidad del Parque Omora para lograr metas significativas en el largo plazo, es evaluada no solo por sus estudios sobre la diversidad biocultural, sino que también por su efectividad para resolver desafíos de la conservación biocultural, interrelacionando procesos educacionales y de toma de decisiones.

Este trabajo ha forjado maneras innovadoras y efectivas para ampliar la definición del componente social (“S”) en las redes SESELP (Anderson et al. 2008). La aproximación de filosofía ambiental de campo y su ciclo de cuatro pasos para integrar investigación, educación y conservación biocultural ha sido crítica para vincular programas de postgrado estadounidenses y chilenos a través de metodologías comparables, que permiten al Parque Omora educar una cohorte de nuevos estudiantes de postgrado quienes se preparan para interrelacionar conceptos ecológicos y éticos, diversidad biológica y cultural, y continuar adaptando el programa en el largo plazo para abordar los desafíos que plantee la próxima década con miras al 2020.

\section{MATERIAL COMPLEMENTARIO}

La versión en inglés de este artículo está disponible como Material Complementario online en http://rchn.biologiachile.cl/ suppmat/2010/1/MC_Rozzi_et_al_2010.pdf

\section{AGRADECIMIENTOS}

Los autores agradecen a las numerosas personas e instituciones que han colaborado con el programa del Parque Etnobotánico Omora. Los mapas fueron preparados por María Rosa Gallardo, Laboratorio SIG, Universidad de Magallanes. La investigación y proyectos que han generado los resultados presentados en este artículo son fruto de la colaboración con múltiples instituciones y han contado con el apoyo de los proyectos PFB-23 (Basal-CONICYT), P05-002 (ICMMIDEPLAN), 08-CTU01-22 (INNOVA-CORFO) y OISE 0854350 (US-NSF). Este trabajo es una contribución del Programa de Conservación Biocultural Subantártica (Universidad de Magallanes, Instituto de Ecología y Biodiversidad de Chile y University of North Texas, http://www.chile.unt.edu).

\section{LITERATURA CITADA}

ADGER N, HEAKIN \& A WINKELS (2009) Nested and teleconnected vulnerabilities to environmental change. Frontiers in Ecology and the Environment 7: 150-157.

AILLAPAN L \& R ROZZI (2001) Veinte poemas alados de los bosques nativos del sur de Chile (also with a version in english: Twenty winged poems from the native forests of southern Chile). Two CDs of indigenous poems by the Mapuche shaman Lorenzo Aillapan, recorded in the in the forests of southern Chile in combination with bird vocalizations. Contain a book with an explanatory preface and bilingual text Mapudungun-English of the poems with illustration of the birds by D Martínez. Editorial Plaza y Valdés, México.

AILLAPAN L \& R ROZZI (2004) Una etno-ornitología mapuche contemporánea: Veinte poemas alados de los bosques nativos de Chile. Ornitología Neotropical 15: 419-434.

ABA (2006) Principles of birding ethics. En: ABA Big Day Report \& ABA Illustrated Report. American Birding Association.

ANDERSON CB \& R ROZZI (2000) Bird assemblages in the southernmost forests in the world: Methodological variations for determining species composition. Anales del Instituto de la Patagonia 28: 89-100.

ANDERSON CB, R ROZZI, C ELPHICK \& S MCGEHEE (2002) El programa Omora de anillamiento de las aves en los bosques subantárticos: La estandarización del tamaño de anillos apropiados para las aves de la Región de Magallanes. Boletín Chileno de Ornitología 9: 2-11. 
ANDERSON CB, R ROZZI, JC TORRES-MURA, SM MCGEHEE, MF SHERRIFFS, E SCHÜTTLER \& AD ROSEMOND (2006a) Exotic vertebrate fauna in the remote and pristine sub-Antarctic Cape Horn Archipelago, Chile. Biodiversity and Conservation 15: 3295-3313.

ANDERSON CB, CR GRIFFITH, AD ROSEMOND, R ROZZI \& O DOLLENZ (2006b) The effects of invasive North American beavers on riparian plant communities in Cape Horn, Chile: Do exotic beavers engineer differently? Biological Conservation 128: 467-474.

ANDERSON CB, GE LIKENS, R ROZZI, JR GUTIERREZ, JJ ARMESTO \& A POOLE (2008) Integrating science and society through longterm socio-ecological research. Environmental Ethics 30: 295-312.

ANDERSON CB, G MARTÍNEZ-PASTUR, MV LENCINAS, PK WALLEN, MC MOORMAN \& AD ROSEMOND (2009) Do introduced North American beavers engineer differently in southern South America? - An overview with implications for restoration. Mammal Review 39: 33-52.

ANDERSON CB, R ROZZI, JJ ARMESTO \& JR GUTIÉRREZ (2010) Introducción. Construyendo una Red Chilena para Estudios Socioecológicos a Largo Plazo: Avances, enfoques y relevancia. Revista Chilena de Historia Natural 83: 1-11.

ARANGO X, R ROZZI, F MASSARDO, CB ANDERSON \& JT IBARRA (2007) Discovery and implementation of Magellanic woodpecker (Campephilus magellanicus) as an emblematic species: A biocultural approach for conservation in Cape Horn Biosphere Reserve. Magallania 35: 71-88.

ARMESTO JJA (1990) Estudios a largo plazo: Una prioridad para la investigación ecológica de hoy. Revista Chilena de Historia Natural 63: 7-9.

ARMESTO JJA (1995) Justification and needs for a long-term research program in ecology in Chile. Revista Chilena de Historia Natural 68: 5-11.

BARBER M \& P MATSON (2000) Ten Years of the Sustainable Biosphere Initiative. Symposium 8 in the $85^{\text {th }}$ Annual Meeting of the Ecological Society of America, Snowbird, Utah. URL: http:/ /abstracts.co.allenpress.com/pweb/esa2000/ sessions/130.html (accedido Abril 17, 2009).

BARROS E \& J HARCHA (2004) La iniciativa de la Reserva de Biosfera Cabo de Hornos: Análisis de un desafío para el desarrollo sustentable en la provincia Antártica Chilena. En: Rozzi R, F Massardo \& CB Anderson (eds) Reserva de Biosfera Cabo de Hornos una propuesta de conservación y turismo para el desarrollo sustentable en el extremo austral de América: 27-43. Editorial Universidad de Magallanes, Punta Arenas, Chile.

BERGHÖFER U, R ROZZI \& K JAX (2008) Local versus global knowledge: Diverse perspectives on nature in the Cape Horn Biosphere Reserve. Environmental Ethics 30: 273-294.

BORMANN H \& S KELLERT (1991) Ecology, economics, ethics: The broken circle. Yale University Press, New Haven.

BROOME J (2008) The ethics of climate change. American Scientists 96: 97-102

BROWN CE, CB ANDERSON, S IPPI, MF SHERRIFFS \& R ROZZI (2007) The autecology of the fío-fío (Elaenia albiceps). Anales del Instituto de la
Patagonia 35: 29-40.

CALLICOTT JB, R ROZZI, L DELGADO, M MONTICINO, M ACEVEDO \& P HARCOMBE (2007) Biocomplexity and conservation of biodiversity hotspots: Three case studies from the Americas. Philosophical transactions of the royal society b-biological sciences 362: 321-333.

CARMONA MR, JC ARAVENA, MA BUSTAMANTESÁNCHEZ, JL CELIS-DIEZ, A CHARRIER, et al. (2010) Estación Biológica Senda Darwin: Investigación ecológica de largo plazo en la interfase ciencia-sociedad. Revista Chilena de Historia Natural 83: 113-142.

CHACÓN M (2002) Turismo en Chile. Serie Estudios $\mathrm{N}^{\circ} 270$. Biblioteca del Congreso Nacional de Chile - Departamento de Estudios, Extensión y Publicaciones. Valparaíso, Chile.

CONAMA (2002) Informe sitios prioritarios para la conservación de la biodiversidad. Comisión Nacional del Medio Ambiente (CONAMA), Región de Magallanes y Antártica Chilena, Punta Arenas, Chile.

DAILY GC (1997) Nature's services: Societal dependence on natural ecosystems: 1-10. Island Press, Washington DC.

DALY HE \& KN TOWNSEND (1993) Valuing the Earth: Economics, ecology, ethics. MIT Press, Cambridge, Massachusetts.

DAVY BJ (2007) An other face of ethics in Levinas. Ethics \& The Environment 12: 39-67.

DÍAZ H (2006) La metáfora en la definición científica. En: Di Stefano M (ed) Metáforas en uso: 105114. Biblós, Buenos Aires.

DUSSELL E (1999) "Sensibility" and "Otherness" in Emmanuel Lévinas. Philosophy Today 43: 126134.

ELLIOT R (1994) Extinction, restoration, naturalness. Environmental Ethics 16: 135-144.

ELLIS JC, JM FARIÑA \& JD WITMAN (2006) Nutrient transfer from sea to land: The case of gulls and cormorants in the Gulf of Maine. Journal of Animal Ecology 75: 565-574.

ENGEL E (1978) A taxonomic and phytogeographic study of Brunswick Peninsula (Strait of Magellan) Hepaticae and Anthoceratae. Field Museum of Natural History, Chicago IL.

ESTÉVEZ RA, DA SOTOMAYOR, AK POOLE \& JC PIZARRO (2010) Formando una nueva generación de investigadores capaces de integrar los aspectos socioecológicos en conservación biológica. Revista Chilena de Historia Natural 83: 17-25.

FALK D, M PALMER \& J ZEDLER (eds) (2006) Foundations of restoration ecology. Island Press, Washington DC.

FARBER S, R COSTANZA, DL CHILDERS, J ERICKSON, K GROSS et al. (2006) An ecosystem services framework that links science, values, and environmental decision making. BioScience 56: 121-133.

FEINSINGER P (2001) Designing field studies for biodiversity conservation. Island Press, Washington DC.

FEINSINGER P, L MARGUTTI \& R OVIEDO (1997) Schoolyards and nature trails: Ecology education outside the university. Trends in Ecology \& Evolution 12: 115-120.

FENNELL DA \& K EBERT (2004) Tourism and the precautionary principle. Journal of Sustainable Tourism 12: 461-479 
FLAVIN C (2007) Preface. En: Starke L (ed) State of the World 2007: Our urban future: xxiii-xxv. Worldwatch Institute, Wahington DC.

GARDINER S (2004) Ethics and global climate change. Ethics 114: 555-600.

FRANKLIN JF, CS BLEDSOE \& JT CALLAHAN (1990) Contributions of the Long-Term ecological research program. BioScience 40: 509-523.

FUENTES ER \& JC CASTILLA (1991) Cambio global, desarrollo sustentable y conservación de la biodiversidad: ¿Qué podemos hacer? Revista Chilena de Historia Natural 64: 171-174.

GARCÍA M (2004) Reserva de Biosfera Cabo de Hornos, un desafío para el ecoturismo. En: Rozzi R, F Massardo \& CB Anderson (eds) Reserva de Biosfera Cabo de Hornos una propuesta de conservación y turismo para el desarrollo sustentable en el extremo austral de América: 177-204. Editorial Universidad de Magallanes, Punta Arenas, Chile

GOFFINET B, W BUCK, F MASSARDO \& R ROZZI (2006) Los bosques en miniatura del Cabo de Hornos. Ediciones Universidad de Magallanes, Punta Arenas, Chile.

GOLLEY F (1993) The History of the ecosystem: More than the sum of the parts. Yale University Press, New Haven.

GUEVARA S \& J LABORDE (2008) The landscape approach: Designing new reserves for protection of biological and cultural diversity in Latin America. Environmental Ethics 30: 251-262.

GUTIÉRREZ JR, PL MESERVE, DA KELT, A ENGILIS JR, MA PREVITALI, WB MILSTEAD \& FM JAKSIC (2010) Long-term research in Bosque Fray Jorge National Park: Twenty years studying the role of biotic and abiotic factors in a Chilean semiarid scrubland. Revista Chilena de Historia Natural 83: 69-98.

HAIDER S \& K JAX (2007) The application of environmental ethics in conservation: A case study from the southernmost tip of the Americas. Biodiversity and Conservation 16: 2559-2573.

HARDIN G (1968) La tragedia de los comunes. En: Ambiente y Desarrollo, Edición especial: Ética Ambiental, Revista de CIPMA: 53-63.

HARGROVE E (1997) Ética ambiental y educación ambiental. Based on a translation of "Environmental ethics and environmental education" by Eugene Hargrove, and edited for Ambiente y Desarrollo XIII: 47-51.

HARGROVE E, MTK ARROYO, PH RAVEN \& H MOONEY (2008) Omora Ethnobotanical Park and the UNESCO Cape Horn Biosphere Reserve. Ecology and Society 13: 49. (en línea) URL: http://www.ecologyandsociety.org/vol13/iss2/ art49/ (accedido Enero 19, 2010).

HARGROVE E (2008) A traditional and multicultural approach to environmental ethics at primary and secondary school levels. Environmental Ethics 30: 263-271.

HERRICK J \& J SARUKHÁN (2007) A strategy for ecology in an era of globalization. Frontiers in Ecology and the Environment 5: 172-181.

HIRSCH-HADORN G, H HOFFMANN-RIEM, S BIBERKLEMM, W GROSSENBACHER-MANSUY, D JOYE, C POHL, U WIESMANN \& E ZEMP (eds) (2008) Handbook of transdisciplinary research. Springer, Heidelberg.

HOLLING CS (2004) From complex regions to complex worlds. Ecology and Society 9: 11. (en línea) URL: http://www.ecologyandsociety.org/ vo19/iss1/art11/ (accedido Enero 19, 2010).

HUNTLEY BJ, E EZCURRA, ER FUENTES, K FUJII, PJ GRUBB et al. (1991) Una biósfera sustentable: El imperativo global. Revista Chilena de Historia Natural 64: 227-235.

IBARRA T, X ARANGO, M GAÑAN \& R ROZZI (2007) Hábitats y habitantes de la cuenca del río Róbalo en el fin del mundo. Edición Ibarra T, Santiago.

IBARRA JT (2007) El visón en Upushwaia: Variaciones estacionales de la avifauna en ambientes de humedal y de su depredación por la especie exótica Mustela vison (Schreber) en isla Navarino, Reserva de Biosfera Cabo de Hornos, Chile. Tesis de Magíster (MSc), Facultad de Agronomía e Ingeniería Forestal, Pontificia Universidad Católica de Chile, Santiago.

IBARRA JT, L FASOLA, DW MACDONALD, R ROZZI \& C BONACIC (2009) Invasive American mink Mustela vison in wetlands of the Cape Horn Biosphere Reserve, southern Chile: What are they eating? Oryx 43: 87-90.

INE-SERNATUR (2008) Informes Anuales de Turismo 1999 - 2008, Turismo Mensual, Estadísticas Económicas, Instituto Nacional de Estadísticas Región de Magallanes y Antártica Chilena. Instituto Nacional de Estadísticas (INE) y Gobierno de Chile - Servicio Nacional de Turismo (SERNATUR) URL: http://www.ine.cl/ c a n a l e s / c hil e e s t a d i s t i co/ estadisticas_economicas/turismo/infoanual/ informesanuales.php (accedido Febrero 9, 2010).

IPPI S, CB ANDERSON, R ROZZI \& CS ELPHICK (2009) Intra-annual variation in subantarctic forest bird communities. Ornitología Neotropical 20: 231-246.

JAX K \& R ROZZI (2004) Ecological theory and values in the determination of conservation goals: Examples from temperate regions of Germany, USA and Chile. Revista Chilena de Historia Natural 77: 349-366.

JOFRE J (2009). Distribución y reproducción de briófitas en la Reserva de Biosfera Cabo de Hornos. Tesis de Magíster, Universidad de Magallanes, Punta Arenas, Chile.

JOFRE J, F MASSARDO, R ROZZI, B GOFFINET, P MARINO, R RAGUSO \& N NAVARRO (2010) Fenología de la fase esporofítica de Tayloria dubyi (Splachnaceae) en las turberas de la Reserva de Biosfera Cabo de Hornos. Revista Chilena de Historia Natural 83: 195-206.

JORDAN WR, ME GILPIN \& JD ABER (eds) (1987) Restoration ecology: A synthetic approach to ecological research. Cambridge University Press, New York.

KRAUSS M (1992) The world's languages in crisis. Language 68: 4-10.

LA PRENSA AUSTRAL (2009a) Culpan a concesión a privados de sector de Bahía Wulaia. Hallan importantes sitios arqueológicos devastados en zona de Cabo de Hornos. Edición 10 de octubre. Punta Arenas, Chile.

LA PRENSA AUSTRAL (2009b). Carta al director. Deterioro arqueológico. Edición 28 de octubre. Punta Arenas, Chile.

LAKOFF G \& M JOHNSON (1980) The metaphorical structure of the human conceptual system. Cognitive Science: A Multidisciplinary Journal 4: 195-208. 
LEOPOLD A (1949) La ética de la Tierra. En: Ambiente y Desarrollo, Edición especial: Ética Ambiental, Revista de CIPMA: 29-40.

LEOPOLD C (2004) Living with the land ethic. BioScience 54: 149-154.

LEVINAS E (1969) Totality and infinity: An essay on exteriority. Trans. Alphonso Lingis. Duquesne University Press, Pittsburgh, USA.

LIKENS GE (1991) Toxic winds, whose Responsibility? En: FH Bormann \& SR Kellert (eds) Ecology, economics, and ethics: 136-152. Yale University Press, New Haven.

LOUV R (2005) Last child in the woods: Saving our children from nature-deficit disorder. Algonquin Books, New York.

LOWMAN M \& DC RANDLE (2009) Ecological mentoring: Inspiring future scientists. Frontiers in Ecology and the Environment 7: 119-119

LUBCHENCO J, AM OLSON, LB BRUBAKER, SR CARPENTER, MM HOLLAND et al. (1991a) The sustainable biosphere initiative: An ecological research agenda. Ecology 72: 371-412.

LUBCHENCO J, AM OLSON, LB BRUBAKER, SR CARPENTER, MM HOLLAND et al. (1991b) Iniciativa para una biósfera sustentable: Una agenda de investigación ecológica. Revista Chilena de Historia Natural 64: 175-226.

MACINTYRE A (1984) After virtue: A study in moral theory. Second edition. University of Notre Dame Press, Notre Dame, Indiana, USA.

MAFFI L (2001) Language, knowledge, and indigenous heritage rights. En: Maffi L (ed) On biocultural diversity: Linking language, knowledge and the environment: 412-432. Smithsonian Institution Press, Washington, DC.

MASSARDO F \& R ROZZI (2006) The world's southernmost ethnoecology: Yahgan craftmanship and traditional ecological knowledge. Bilingual english-spanish edition. Ediciones Universidad de Magallanes, Punta Arenas, Chile.

MASSARDO F \& R ROZZI (2004) Etno-ornitología yagán y lafkenche en los bosques templados de Sudamérica austral. Ornitología Neotropical 15: 395-407.

MATTERI C (2000) Southern South America. Biodiversity, centres of diversity, and endemism. En: Hallingbäck T \& N Hodgetts (eds) Mosses, liverworts, and hornwort: Status survey and conservation action plan for bryophytes. IUCN, Gland, Switzerland.

MATURANA (1997) Pensamiento analógico. En: Rozzi R, P Feinsinger \& R Riveros (eds) La enseñanza de la ecología en el entorno cotidiano: 13-19. Módulo de Educación Ambiental. Ministerio de Educación de Chile, Santiago, Chile.

MERINO S, J MORENO, RA VÁSQUEZ, J MARTÍNEZ, I SÁNCHEZ-MONSÁLVEZ et al. (2008) Haematozoa in forest birds from southern Chile: Latitudinal gradients in prevalence and parasite lineage richness. Austral Ecology 33: 329-340.

MILLENNIUM ECOSYSTEM ASSESSMENT (2005) Ecosystems and Human Well-being: Synthesis. Island Press, Washington DC, World Resources Institute. URL: http://www.millennium assessment.org/en/products.aspx (accedido Abril 17, 2009).

MITTERMEIER RA， CG MITTERMEIER, TM BROOKS, JD PILGRIM, WR KONSTANT, GAB DA FONSECA \& C KORMOS (2003) Wilderness and biodiversity conservation. Proceedings of the National Academy USA 100: 10309-10313.

MOONEY HA \& SA LEVIN (1991) Preface to the sustainable biosphere initiative. Ecology 72: 371372.

NAESS A (1973) Los movimientos de la ecología superficial y la ecología profunda: Un resumen. En: Ambiente y Desarrollo. Edición Especial: Ética Ambiental. Revista de Ambiente y Desarrollo: 98-105.

OELSCHLAEGER M \& R ROZZI (1998) El nudo gordiano interdisciplinario: Un desafío para la sustentabilidad. Ambiente y Desarrollo 14: 71-81.

OJEDA J, T CONTADOR, S ROSENFELD, CB ANDERSON, A MANSILLA \& J KENNEDY (2010) Guía para la identificación de invertebrados marinos y dulceacuícolas de la Reserva de Biosfera Cabo de Hornos, Chile. Ediciones Universidad de Magallanes, Punta Arenas, Chile.

PALMER MA \& S FILOSO (2009) Restoration of ecosystem services. Science 325: 575-576.

PICKETT STA \& ML CADENASSO (2002) The ecosystem as a multidimensional concept: Meaning, model, and metaphor. Ecosystems 5: $1-10$

PISANO E (1980) Catálogo de la flora vascular del archipiélago del Cabo de Hornos. Anales del Instituto de la Patagonia 11: 152-189.

ROZZI R (1997) Enseñar a los niños a ser ciudadanos, no meramente consumidores: El aporte de Hargrove a la educación ambiental en Chile. Ambiente y Desarrollo 13: 52.

ROZZI R \& A POOLE (2008) Biocultural and linguistic diversity. En: Callicott B \& R Frodeman (eds) Encyclopedia of environmental ethics and philosophy, Volume 1: 100-104. MacMillan Reference Book - Gale, Cengage Learning, Farmington Hills, Michigan.

ROZZI R (2004) The Cape Horn archipelago territory: A biocultural treasure at the south of the world. En: Rozzi R, F Massardo \& C Anderson (eds) The Cape Horn Biosphere Reserve: A proposal for conservation and tourism to achieve sustainable development at the southern end of the Americas: 11-25. Bilingual english-spanish edition. Ediciones de la Universidad de Magallanes, Punta Arenas, Chile.

ROZZI R (1999) The reciprocal link between evolutionary-ecological sciences and environmental ethics. BioScience 49: 911-921.

ROZZI R (2001) Ética ambiental: Raíces y ramas latinoamericanas. En: Primack R, R Rozzi, P Feinsinger, R Dirzo \& F Massardo (eds) Fundamentos de conservación biológica: Perspectivas latinoamericanas: 311-359. Fondo de Cultura Económica, México.

ROZZI R (2004) Implicaciones éticas de narrativas yaganes y mapuches sobre las aves de los bosques templados de Sudamérica austral. Ornitología Neotropical 15 (suppl.): 435-444.

ROZZI R (2006) Biodiversidad en la educación informal: Turismo sustentable en Cabo de Hornos. En: CONAMA (eds) Biodiversidad de Chile: Patrimonio y desafíos: 628-630. Comisión Nacional del Medio Ambiente, Santiago, Chile.

ROZZI R (2007) Future environmental philosophies and their biocultural conservation interfaces. Ethics and the Environment 12: 142-145.

ROZZI R (en prensa) Recuperando la raíz común de 
hábitats-hábitos-habitantes: Una unidad ecosistémica-cultural ancestral para un nuevo paradigma ético de la sostenibilidad. Argumentos de Razón Técnica.

ROZZI R \& P FEINSINGER (2001) Desafíos para la conservación biológica en Latinoamérica. En: Primack R, R Rozzi, P Feinsinger, R Dirzo \& F Massardo (eds) Fundamentos de conservación biológica: Perspectivas latinoamericanas: 661688. Fondo de Cultura Económica, México.

ROZZI R, P FEINSINGER \& R RIVEROS (1997) La enseñanza de la ecología en el entorno cotidiano. Módulo de Educación Ambiental. Ministerio de Educación de Chile, Santiago, Chile.

ROZZI R \& M SHERRIFFS (2003) El visón (Mustela vison Schreber, Carnivora: Mustelidae), un nuevo mamífero exótico para la Isla Navarino. Anales Instituto Patagonia 31: 97-104.

ROZZI R, CB ANDERSON, F MASSARDO \& J SILANDER JR (2002). Diversidad biocultural subantártica: Una mirada desde el Parque Etnobotánico Omora. Chloris chilensis 4 (en línea) URL: http://www.chlorischile.cl/ (accedido Enero 19, 2010).

ROZZI R, F MASSARDO, CB ANDERSON, S MCGEHEE, G CLARK et al. (2003a) Guía multiétnica de aves de los bosques templados de Sudamérica austral. Editorial Fantástico Sur, Universidad de Magallanes, Punta Arenas.

ROZZI R, F MASSARDO, J SILANDER, CB ANDERSON \& A MARIN (2003b) Conservación biocultural y ética ambiental en el extremo austral de América: Oportunidades y dificultades para el bienestar ecosocial. En: Figueroa E \& J Simonetti (eds) Biodiversidad y Globalización: 51-85. Editorial Universitaria, Santiago, Chile.

ROZZI R, JM DRAGUICEVIC, X ARANGO, M SHERRIFFS, S IPPI et al. (2005) Desde la ciencia hacia la conservación: El programa de educación y ética ambiental del Parque Etnobotánico Omora. Revista Ambiente y Desarrollo 21: 20-29.

ROZZI R, F MASSARDO, ANDERSON CB, K HEIDINGER \& JA SILANDER (2006a) Ten principles for biocultural conservation at the southern tip of the Americas: The approach of the Omora Ethnobotanical Park. URL: http:// www.ecologyandsociety.org/vol11/iss1/art43/ (accedido Enero 17, 2010).

ROZZI R, F MASSARDO, A BERGHÖFER, C ANDERSON, A MANSILLA et al. (2006b) La Reserva de Biosfera Cabo de Hornos. Programa MaB-UNESCO. Ediciones Universidad de Magallanes, Punta Arenas.

ROZZI R, F MASSARDO, A MANSILLA, CB ANDERSON, A BERGHÖFER et al. (2007) La Reserva de Biosfera Cabo de Hornos: Un desafío para la conservación de la biodiversidad e implementación del desarrollo sustentable en el extremo austral de América. Anales del Instituto de la Patagonia, Ciencias Naturales 35: 55-62.

ROZZI R, X ARANGO, F MASSARDO, CB ANDERSON, K HEIDINGER \& K MOSES (2008a) Field environmental philosophy and biocultural conservation: The Omora Ethnobotanical Park's environmental education program. Environmental Ethics 30: 325-336.

ROZZI R, JJ ARMESTO, B GOFFINET, W BUCK, F MASSARDO et al. (2008b) Changing biodiversity conservation lenses: Insights from the subAntarctic non-vascular flora of southern South America. Frontiers in Ecology and the Environment 6: 131-137.

RUBENSTEIN DI (1993) Science and the pursuit of a sustainable world. Ecological Applications 3: 585587.

SCHUTTLER E (2009) Populationsökologie, auswirkungen und soziale akzeptanz des Amerikanischen minks (Mustela vison), einer neuen invasiven art auf der Insel Navarino, KapHoorn-Biosphärenreservat, Chile. Ph.D. Dissertation, University of Munich, Alemania.

SCHUTTLER E, J CARCAMO \& R ROZZI (2008) Diet of the American mink Mustela vison and its potential impact on the native fauna of Navarino Island, Cape Horn Biosphere Reserve, Chile. Revista Chilena de Historia Natural 81: 585-598.

SCHUTTLER E, R KLENKE, S MCGEHEE, R ROZZI \& K JAX (2009) Vulnerability of ground-nesting waterbirds to predation by invasive American mink in the Cape Horn Biosphere Reserve, Chile. Biological Conservation 142: 1450-1460.

SMITH D (2004) Issues and trends in higher education biology fieldwork. Journal of Biological Education 39: 6-10.

UNESCO (1996) Reservas de Biosfera. La estregía de Sevilla y el marco estatuario de la red mundial. Programa Hombre y la Biosfera. Unesco, Paris.

UNT (2008) Five-year strategic plan 2008-2013, University of North Texas. URL: http:// vpaa.unt.edu/strategic-plan.htm (accedido Enero 19, 2010)

VENEGAS C \& W SIELFELD (1998) Catálogo de los vertebrados de la región de Magallanes y Antártica Chilena. Editorial Universidad de Magallanes, Punta Arenas, Chile.

VILLAGRÁN C, G HAZLE \& F BARRERA (2005) Hepáticas y antocerotes del archipiélago de Chile. Museo Nacional de Historia Natural, Santiago, Chile.

WHITE JR L (1967) Raíces históricas de nuestra crisis ecológica. En: Edición Especial: Ética Ambiental, Revista Ambiente y Desarrollo 23: 78-86.

ZÁRRAGA C, F MASSARDO \& R ROZZI (2006) Hen larmameuti hen maruti intien: Diccionario infantil yagán (Yahgan children dictionary). Ediciones Universidad de Magallanes, Punta Arenas, Chile. 


\title{
APÉNDICE
}

Las tres áreas temáticas principales de la investigación transdisciplinaria a largo plazo ecológica y filosófica del Programa del Parque Etnobotánico Omora.

\author{
Área general de in- Investigación con énfasis ecológico Investigación con énfasis filosófico \\ vestigación
}

Diversidad biológica subantártica y diversidad sociocultural de las percepciones acerca de la biodiversidad

Interacciones ecológicas entre diversos grupos de organismos, incluyendo a los seres humanos, los diversos grupos socioculturales y sus éticas ambientales

Biotas y culturas nativas y exóticas
Muestreos y censos de flora y fauna en el largo plazo, considerando variaciones estacionales y heterogeneidad de hábitats terrestres, dulceacuícolas y marinosi. Este tipo de estudios contrasta con investigaciones ecológicas previas que se han efectuado la región de Cabo de Hornos, que han sido conducidas casi exclusivamente durante períodos cortos, especialmente en el verano y abordando unos pocos grupos taxonómicos en sitios muy puntualesii.

Investigación sobre interacciones ecológicas singulares en la ecorregión subantártica. Estos estudios han descubierto niveles notablemente bajos niveles de endoparasitismo en paseriformes, altos grados de generalismo en la dieta de aves del bosque, e interacciones novedosas como la entomofilia en musgos de la familia Splachnaceae cuyas esporas serían dispersadas por dípteros y se establecerían sobre fecas de gansos silvestres ${ }^{\text {iv. }}$.

Estudios sobre especies de mamíferos exóticos invasores, especialmente castor (Castor canadensis) y visón (Neovison vison) y sus impactos sobre ecosistemas forestales y avifauna que nidifica en el suelo, respectivamente ${ }^{\text {vii. }}$.
Análisis de las cosmovisiones amerindias, principalmente enfocado en las culturas yagán y mapuche, a través del estudio de la etnobotánica, etnozoología y sus implicaciones para la ética ambientaliii.

Estudios sobre conocimientos y perspectivas ecológicas y éticas acerca de la naturaleza albergados por distintos grupos socioculturales, instituciones y disciplinas ${ }^{\mathrm{v}}$. Luego se realizan análisis comparativos entre estos conocimientos, perspectivas y valores ecológicos, y de ellos con modos de comprensión y valoración derivados de las ciencias ecológicas y de la ética ambientalvi

Filosofía ambiental multicultural, incluyendo registro y análisis de prácticas y formas de conocimiento ecológico local y sus implicancias éticas, como también la traducción del español al inglés (y viceversa) de textos de filosofía ambiental latinoamericana con énfasis en la ética ecológica de Latinoamérica ${ }^{\text {viii }}$.

i Goffinet et al. 2006, Rozzi et al. 2006b, Ippi et al. 2009, Mansilla et al. datos no publicados, Kennedy et al. datos no publicados.

ii Anderson \& Rozzi 2000, Anderson et al. 2002, Rozzi et al. 2006b.

iii Massardo \& Rozzi 2004, 2006, Rozzi et al. 2003a, Aillapan \& Rozzi 2001, 2004, Rozzi 2001, 2004.

iv Brown et al. 2007, Merino et al. 2008, Jofre 2009, Jofre et al. 2010.

${ }^{v}$ Rozzi et al. 2001, 2003b, 2008b, Haider \& Jax 2007, Berghoefer et al. 2008.

vi Jax \& Rozzi 2004, Rozzi \& Massardo 2001, Rozzi 2010.

vii Anderson et al. 2006a, 2006b, 2009, Ibarra et al. 2009, Schüttler et al. 2009.

viii Rozzi 2007, 2010b. 